\title{
A parametric database study of no-erosion filter tests
}

1 Piltan Tabatabaie Shourijeh BSc, MSc, PhD Assistant Professor, Department of Civil and Environmental Engineering, Shiraz University of Technology, Shiraz, Iran

2 Abbas Soroush BSc, MSc, PhD

Professor, Department of Civil and Environmenta Engineering, Amirkabir University of Technology (Tehran Polytechnic), Tehran, Iran (corresponding author: soroush@aut.ac.ir)
3 Sina Shams Molavi BSc, MSc

Former MSc Student, Department of Civil and Environmental Engineering, Amirkabir University of Technology (Tehran Polytechnic), Tehran, Iran

4 Sina Ramezani Fouladi BSc, MSC

Former MSc Student, Department of Civil and Environmental Engineering, Amirkabir University of Technology (Tehran Polytechnic), Tehran, Iran
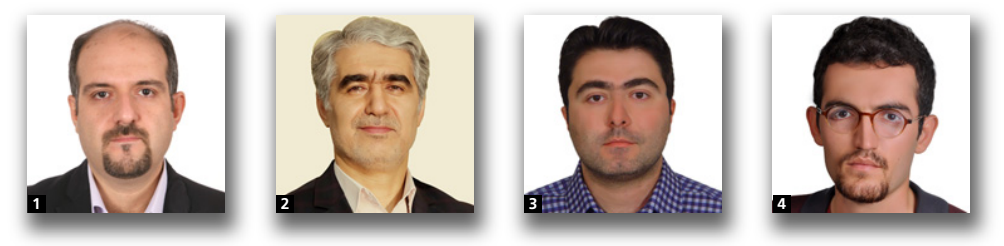

Modern filter design procedures for embankment dams respect criteria stemming from no-erosion filter (NEF) tests. The widespread application of NEF testing has provided experimental evidence of some deviations from the established filter criteria. This paper provides a complementary update to similar database studies of NEF test results. A large database of NEF tests, consisting of $\mathbf{2 5 8}$ group I and group II core soils (i.e. having more than $\mathbf{3 5 \%}$ fines content) was analysed and the effects of various core soil characteristics (gradation, fines content, clay content, plasticity index and dispersivity) on experimentally defined no-erosion boundary filters were assessed. The database is unique, as it compiles the largest set of NEF test results. Through rigorous statistical and parametrical analysis, this paper critically compares current filter design criteria with experimental results and provides new insights that may assist and improve current procedures of critical filter design.

\section{Notation}

$A_{\text {r }}$

$C_{\mathrm{c}} \quad$ clay content, percentage finer than $0.005 \mathrm{~mm}$ in adjusted gradation

$D_{i} \quad$ filter particle diameter with $i \%$ finer by mass

$D_{15 \mathrm{~b}} \quad$ no-erosion boundary filter size resulting from NEF test on a base soil

$d_{i} \quad$ base soil particle diameter with $i \%$ finer by mass, for the adjusted gradation curve with maximum size of $4.75 \mathrm{~mm}$

$F_{\text {c }} \quad$ fines content, percentage finer than $0.075 \mathrm{~mm}$ in adjusted gradation

$M_{\text {c }} \quad$ silt content, percentage between 0.005 $\mathrm{mm}$ and $0.075 \mathrm{~mm}$ in adjusted gradation

$m_{\mathrm{a}} \quad$ arithmetic mean

$N \quad$ total number of data points in analysis

$n \quad$ number of data points per reference

$S_{\mathrm{c}} \quad$ fine to medium sand content, percentage between $0.075 \mathrm{~mm}$ and $1.18 \mathrm{~mm}$ in adjusted gradation standard deviation

\section{Introduction}

Statistical surveys of embankment dam failures reveal that internal erosion, particularly from the embankment, has been responsible for nearly half of dam failures, with an even higher percentage experiencing non-catastrophic erosion-related incidents/accidents (Foster et al., 1998; Fry, 2016; Fry et al., 2012; ICOLD, 2017; Richards and Reddy, 2007).

To some extent, the initiation of erosion depends on the characteristics of embankment materials (e.g. the core), and filters are designed and constructed as defence barriers to control/suppress internal erosion. When filters fail, that is they fail to stop erosion, internal erosion continuation and progression (to form a pipe or cause sloughing) is the likely scenario that may eventuate in dam breach (Fell et al., 2003, 2015; ICOLD, 2017). The principal role that filters play in dam safety, along with their usually high production and construction costs, make optimal filter design and substantiation a topic that is subject to much scientific debate.

Numerous filter design criteria have been proposed, among which the criteria presented by Sherard and Dunnigan (1985, 1989) are broadly implemented in modern embankment dam engineering. These criteria (see Table 1) stem from extensive no-erosion filter (NEF) tests carried out by Sherard and coworkers at the United States Department of Agriculture Soil Conservation Service in 1980-1985. Since their initial introduction, the criteria proposed by Sherard and Dunnigan 
Table 1. Proposed filter criteria based on NEF testing

\begin{tabular}{|c|c|c|c|c|c|c|}
\hline \multirow[b]{2}{*}{ Reference } & & \multicolumn{5}{|c|}{ Base soil designation } \\
\hline & & Group I & Group II & & Group III & Group IV \\
\hline \multirow[t]{2}{*}{ Sherard and Dunnigan (1985) } & $F_{c}: \%^{a}$ & $\geq 85$ & $40-85$ & & $<15$ & $15-40$ \\
\hline & Criterion $^{\mathrm{b}}$ & $D_{15} \leq 9 d_{85}$ & $D_{15} \leq 0.7 \mathrm{~mm}$ & & $D_{15} \leq 4 d_{85}{ }^{c}$ & $D_{15} \leq \frac{40-F_{c}}{25}\left(4 d_{85}-0.7\right)+0.7 \mathrm{~mm}$ \\
\hline \multirow[t]{2}{*}{ Foster and Fell (1999) } & $F_{\mathrm{c}}: \%$ & $\geq 85$ & $35-85$ & & $<15$ & $15-35$ \\
\hline & Criterion & $D_{15} \leq 9 d_{85}{ }^{d}$ & $D_{15} \leq 0.7 \mathrm{~mm}^{\mathrm{e}}$ & & $D_{15} \leq 7 d_{85}$ & $D_{15} \leq 1.6\left(\frac{35-F_{c}}{20}\left(4 d_{85}-0.7\right)+0.7 \mathrm{~mm}\right)$ \\
\hline \multirow[t]{2}{*}{ Shourijeh and Soroush (2009) } & $F_{c}: \%$ & $\geq 85$ & $\geq 80$ & $35-80$ & $<15$ & $15-35$ \\
\hline & Criterion & $D_{15} \leq 9 d_{85}{ }^{f, g}$ & $\begin{array}{l}D_{15} \leq \text { minimum of } 0.7 \mathrm{~mm} \\
\text { and } 6.4 d_{85}{ }^{9}\end{array}$ & $D_{15} \leq 0.7 \mathrm{~mm}^{\mathrm{e}}$ & $D_{15} \leq 4 d_{85}$ & $D_{15} \leq \frac{35-F_{\mathrm{c}}}{20}\left(4 d_{85}-0.7\right)+0.7 \mathrm{~mm}$ \\
\hline \multirow[t]{2}{*}{ USBR (2011) and FEMA (2011) } & $F_{c}: \%$ & $\geq 85$ & $40-85$ & & $<15$ & $15-40$ \\
\hline & Criterion & $D_{15} \leq 9 d_{85}{ }^{h}$ & $D_{15} \leq 0.7 \mathrm{~mm}^{\mathrm{e}}$ & & $D_{15} \leq 4 d_{85}$ & $D_{15} \leq \frac{40-F_{c}}{25}\left(4 d_{85}-0.7\right)+0.7 \mathrm{~mm}^{\mathrm{e}}$ \\
\hline \multirow[t]{2}{*}{ Fell et al. (2015) } & $F_{\mathrm{c}}: \%$ & $\geq 85$ & $35-85$ & & $<15$ & $15-35$ \\
\hline & Criterion & $D_{15} \leq 9 d_{85}^{i}$ & $D_{15} \leq 0.7 \mathrm{~mm}^{\mathrm{e}}$ & & $D_{15} \leq 4 d_{85}$ & $D_{15} \leq \frac{35-F_{c}}{20}\left(4 d_{85}-0.7\right)+0.7 \mathrm{~mm}$ \\
\hline \multirow[t]{2}{*}{ This study } & $F_{c}: \%$ & $\geq 85$ & $\geq 80$ & $35-80$ & $<15$ & $15-35$ \\
\hline & Criterion & $D_{15} \leq 9 d_{85}{ }^{f, i}$ & $\begin{array}{l}D_{15} \leq \text { minimum of } 0.5 \mathrm{~mm} \\
\text { and } 5 d_{85}{ }^{j}\end{array}$ & $D_{15} \leq 0.7 \mathrm{~mm}^{\mathrm{e}}$ & $D_{15} \leq 4 d_{85}$ & $D_{15} \leq \frac{35-F_{c}}{20}\left(4 d_{85}-0.7\right)+0.7 \mathrm{~mm}$ \\
\hline
\end{tabular}

a\% finer than $0.075 \mathrm{~mm}$ in gradation adjusted to maximum size of $4.75 \mathrm{~mm}$

${ }^{b} d_{85}$ for gradation passing $4.75 \mathrm{~mm}$, in all criteria except for group III base soils which are not broadly graded or gap-graded

$d_{85}$ for entire material gradation

$D_{15} \leq 6.4 d_{85}$ for highly dispersive soils

${ }^{e} D_{15} \leq 0.5 \mathrm{~mm}$ for highly dispersive soils

$D_{15} \leq 6 d_{85}$ for ML and CL-ML soils

${ }^{9} D_{15} \leq 7.5 d_{85}$ for highly dispersive soils

${ }^{n} D_{15} \leq 6.5 d_{85}$ for highly dispersive soils

$D_{15} \leq 6 d_{85}$ for highly dispersive soils

${ }^{\mathrm{i}} D_{15} \leq 0.3 \mathrm{~mm}$ for highly dispersive soils 
$(1985,1989)$ have been widely recommended by various institutions (e.g. FEMA, 2011; ICOLD, 2017; NRCS, 1994; USACE, 2004; USBR, 2011).

Despite general recognition of the criteria listed in Table 1 and subsequent proven dam performances through application of these rules, filter testing is still the most confident and reliable method for filter selection and design (USBR, 2011). The $\mathrm{NEF}$ test is accepted as a proficient filtration test, especially for fine-grained soils. Many researchers have repeated NEF testing to substantiate appropriate filters and assess filter criteria credibility (e.g. Delgado Ramos and Locke, 2000; Delgado Ramos et al., 2012; Foster and Fell, 1999; Khor and Woo, 1989; Shams Molavi et al., 2013; Soroush and Shourijeh, 2004, 2009; Soroush et al., 2006, 2008, 2011e, 2014, 2016; Vakili and Selamat, 2014; Vakili et al., 2015).

However, recently, the abundance of new dam constructions (particularly in developing countries), unfortunate embankment dam internal erosion incidents and rigorous studies involving NEF testing have revealed some anomalies between the accepted 'no-erosion' filter criteria and the observed behaviours of core soils and filters.

The work presented in this paper involved revisiting critical filter design criteria through compilation and analysis of published NEF test results. To this end, a similar investigation presented by Shourijeh and Soroush (2009) was updated with NEF data published in the last decade and subjected to more rigorous statistical and parametric analyses. The paper is organised into four main sections. First, previous database studies of filtration tests are briefly reviewed. The NEF test database under study is then introduced and its particular facets are elaborated. Thereafter, extensive statistical and parametric analyses on core (base) soils and corresponding 'no-erosion' filters is performed. Finally, modifications to the available criteria and guidelines for critical filter design are suggested.

\section{Database studies of soil filtration}

The NEF criteria in Table 1 are principally inferences drawn from laboratory experiments. Accordingly, Table 1 designates base soils in four groups (groups I to IV) based on their fines content (i.e. passing $75 \mu \mathrm{m}$ ) after the gravel component is sifted out. This is done by graphically regrading the base soil gradation to $4.75 \mathrm{~mm}$ maximum size. It should be noted that regrading is not required when the original base soil gradation has less than $15 \%$ fines content (passing $75 \mu \mathrm{m}$ ) and is 'neither gap-graded nor broadly graded' (USBR, 2015). Foster and Fell (1999) carefully examined the original NEF testing programme reported by Sherard and Dunnigan $(1985,1989)$ and detected a total of $162 \mathrm{NEF}$ tests on 65 base soils (28 from group I, 19 from group II, seven from group III and 11 from group IV). The confidence level and reliability of the proposed criteria (Table 1) would be enhanced with the analysis and evaluation of more soils (from reliable filtration tests).
Foster and Fell (1999) outlined an extensive and thorough investigation of approximately 700 filtration tests, considering all feasible filtration test results (i.e. successful, unsuccessful and intermediate). The detailed and sophisticated analysis conducted by Foster and Fell (1999, 2001) demarcated 'no', 'some', 'excessive' and 'continuing' erosion boundaries for soil filtration, which provided a platform for probabilistic studies of internal erosion and piping in embankment dams (Fell et al., 2008, 2015; ICOLD, 2017). Table 1 shows the revised filter criteria proposed by Foster and Fell (1999).

Delgado Ramos et al. (2006) compiled a large database of filtration tests on group I and group II base soils. In all, 688 tests were investigated, of which 492 were NEF tests 105 tests conducted by Sherard and Dunnigan (1985, 1989), 47 tests reported by Foster and Fell (1999) and 340 performed by Delgado Ramos (2000). Similar to the work of Foster and Fell (1999), Delgado Ramos et al. (2006) focused on determining transitional boundaries between unsuccessful and successful base soil/filter behaviours. In addition, Delgado Ramos et al. (2006, 2016) suggested considering filter permeability in filter design. This, however, was discouraged by Fell et al. (2015) because measuring and controlling filter permeability is generally difficult in practical engineering problems.

Shourijeh and Soroush (2009) collated a large filtration database wherein (a) only NEF tests were considered, excluding other testing strategies, and $(b)$ a 'no-erosion' boundary filter and its associated $D_{15 \mathrm{~b}}$ were considered for each base soil. By definition the boundary filter, $D_{15 \mathrm{~b}}$ is the $D_{15}$ of the coarsest filter that prevents erosion in NEF testing (i.e. leads to no erosion for the base soil). By focusing on base (core) soils, a total of 152 group I and group II base soils and the corresponding $D_{15 \mathrm{~b}}$ values determined through NEF testing were studied by Shourijeh and Soroush (2009). This work was founded on the proposition by Sherard and Dunnigan (1989: p. 945) that 'the filter boundary $D_{15 \mathrm{~b}}$ can be considered a property of the base soil in the same sense that results of tests to determine the Atterberg limits and effective shear strength parameters are considered properties of the impervious soil'.

In later sections of this paper, the study of Shourijeh and Soroush (2009) is expanded to include more data and the results are studied statistically and discussed in more detail.

\section{Database specifications}

The database under study consisted of 258 group I and group II core (base) soils and their corresponding 'no-erosion' filters determined from NEF testing. The portfolio of contributing references, alongside a concise description of their main NEF testing procedural specifications, is presented in Table 2, which is updated from the previous study of Shourijeh and Soroush (2009). 
Table 2. Inventory of NEF testing research incorporated in the database

\begin{tabular}{|c|c|c|c|c|c|c|c|}
\hline \multirow[b]{2}{*}{ Investigator } & \multicolumn{5}{|c|}{ NEF test information } & \multicolumn{2}{|c|}{$\begin{array}{c}\text { Number of base soils } \\
\text { per group }\end{array}$} \\
\hline & $\phi_{\mathrm{A}}: \mathrm{mm}$ & $L_{\mathrm{B}}: \mathrm{mm}$ & $L_{\mathrm{F}}: \mathrm{mm}$ & $\phi_{\mathrm{h}}: \mathrm{mm}$ & $P_{\mathrm{w}}: \mathrm{kPa}$ & Group I & Group II \\
\hline \multirow[t]{2}{*}{ Sherard and Dunnigan $(1985,1989)$} & 100 & 25 & $80-100$ & 1 & 410 & 23 & 15 \\
\hline & 280 & 100 & NA & $5-10$ & & & \\
\hline Khor and Woo (1989) & 170 & 25 & 130 & $1 \cdot 5$ & 400 & - & 9 \\
\hline Rowhani (1996) & 139 & 25 & 100 & 1 & $300-450$ & - & 10 \\
\hline Khavas (1998) & 167 & 90 & 110 & 5 and 10 & $400-500$ & - & 4 \\
\hline \multirow{2}{*}{ Foster and Fell (1999) } & 125 & 25 & 150 & 1 and 2 & $240-300$ & - & 6 \\
\hline & 205 & 100 & 200 & 5 & & & \\
\hline Nasr (1999) & 167 & 90 & 110 & 5 and 10 & $400-500$ & - & 4 \\
\hline Kamali (1999) & 139 & 25 & 100 & 1 & $300-450$ & 20 & 4 \\
\hline Delgado Ramos (2000) & 80 & 25 & 100 & 1 & 400 & 10 & 7 \\
\hline Hossieni (2000) & 167 & 90 & 110 & 5 and 10 & $400-500$ & - & 3 \\
\hline Locke (2001) & $100-200$ & NA & NA & 1 & $200-600$ & 11 & 4 \\
\hline Mirata and Gürler (2004) & 100 & 25 & 40 & $1 \cdot 5$ & 250 & 1 & 2 \\
\hline USBR (2004) $)^{\mathrm{a}}$ & 267 & 25 & 152 & 2 & 275 & 2 & 3 \\
\hline Farzaneh (2005) & 139 & 25 & 100 & 1 & $300-450$ & 4 & - \\
\hline Soroush and Shourijeh (2005) & 110 & 30 & $120-140$ & 1 & 400 & 11 & - \\
\hline Farzaneh (2007) & 139 & 25 & 100 & 1 & $300-450$ & 4 & - \\
\hline Soroush et al. $(2010 a)^{a}$ & 110 & 30 & $120-140$ & 1 & 400 & 6 & - \\
\hline Soroush et al. $(2010 b)^{a}$ & 110 & 30 & $120-140$ & 1 & 400 & 5 & - \\
\hline Eskandary $(2011)^{a}$ & 140 & 30 & 100 & 1 & 400 & 4 & - \\
\hline Soroush et al. $(2011 a)^{a}$ & 110 & 30 & $120-140$ & 1 & 400 & 6 & 4 \\
\hline Soroush et al. $(2011 b)^{a}$ & 110 & 30 & $120-140$ & 1 & 400 & 7 & 3 \\
\hline Soroush et al. $(2011 c)^{a}$ & 110 & 30 & $120-140$ & 1 & 400 & 6 & - \\
\hline Soroush et al. $(2011 d)^{a}$ & 110 & 30 & $120-140$ & 1 & 400 & 1 & - \\
\hline Soroush et al. $(2012 a)^{a}$ & 110 & 30 & $120-140$ & 1 & 400 & 6 & - \\
\hline Soroush et al. $(2012 b)^{a}$ & 110 & 30 & $120-140$ & 1 & 400 & - & 1 \\
\hline Shams Molavi (2013) & 110 & 30 & $120-140$ & 1 & 400 & 2 & - \\
\hline Soroush et al. $(2015)^{a}$ & 110 & 30 & $120-140$ & 1 & 400 & 8 & - \\
\hline Vakili et al. (2015) & 110 & 25 & 100 & 1 & 400 & 10 & 11 \\
\hline Farzaneh (2015) ${ }^{\mathrm{a}}$ & 139 & 25 & 100 & 1 & $300-450$ & 3 & - \\
\hline Ramezani Fouladi (2016) ${ }^{\mathrm{a}}$ & 110 & 30 & $120-140$ & 1 & 400 & 16 & 2 \\
\hline Total number of base soils in each group & & & & & & 166 & 92 \\
\hline
\end{tabular}

Notes: $L_{B}$, base specimen thickness; $L_{\mathrm{F}}$, filter thickness; NA, not available; $P_{\mathrm{w}}$, water pressure; $\phi_{\mathrm{A}}$, apparatus diameter; $\phi_{\mathrm{h}}$, hole diameter

${ }^{a}$ Entries to NEF database since the work carried out by Shourijeh and Soroush (2009)

For each base soil, the principal properties considered are as follows.

(a) Particle size distribution (i.e. gradation) information, namely $d_{85}$, fines content $F_{\mathrm{c}}$ (= percentage passing $75 \mu \mathrm{m})$, clay content $C_{\mathrm{c}}(=$ percentage finer than $5 \mu \mathrm{m})$, silt content $M_{\mathrm{c}}$ (= percentage particles between $5 \mu \mathrm{m}$ and $75 \mu \mathrm{m}$ ) and fine to medium sand content $S_{\mathrm{c}}$ (= percentage of particles between $75 \mu \mathrm{m}$ and $1.18 \mathrm{~mm}$ ). As in filter design guidelines (Fell et al., 2015; ICOLD, 2017; NRCS, 1994; USBR, 2011), this information represents base soils adjusted (i.e. scalped) to a maximum size of $4.75 \mathrm{~mm}$.

(b) Atterberg limits and related information, specifically the plasticity index (PI), activity ratio $\left(A_{\mathrm{r}}=\mathrm{PI} / \%<2 \mu \mathrm{m}\right)$ and soil denomination as per the unified soil classification system (USCS).

(c) Dispersivity information, including double hydrometer and pinhole test results.
It is worth noting that all this information may not be available for some base soils; in such cases, no attempts were made by the authors to foresee/predict missing data.

Concerning filter properties, only $D_{15 \mathrm{~b}}$ is considered as the sole influential filter parameter in the database. It should be mentioned that, for filter materials, the complete gradation (Foster and Fell, 1999), fines (if any) content (Soroush et al., 2012c), relative compaction (Soroush and Shourijeh, 2009) and permeability (Delgado Ramos et al., 2016) may influence the filtration of base (core) soils. On the whole, such information was not reported in pertinent literature and hence was not sought/considered by the current authors.

Consequently, for each core (base) soil, the database relates a no-erosion boundary filter, that is $D_{15 \mathrm{~b}}$ ( $D_{15}$ of the coarsest filter that prevents erosion), determined from NEF testing to an array of base soil properties. 


\section{Database analysis}

\subsection{Base soil group I: fine silts and clays}

Group I soils with $F_{\mathrm{c}} \geq 85 \%$ are the finest core soils considered for filter design (Table 1). From the results of NEF testing, Sherard and Dunnigan $(1985,1989)$ stated that, for this base soil group, $D_{15 \mathrm{~b}} / d_{85}$ generally ranges from 7 to 12 , and $D_{15} \leq 9 d_{85}$ is considered as the design criterion. While no correlation between $D_{15 \mathrm{~b}}$ and base soil properties (i.e. relative erosion resistance, Atterberg limits and dispersive erosion tendency) could be established, an experimentally defined $D_{15 \mathrm{~b}} / d_{85}$ ratio of 5.7 to 6.2 was observed for low-plasticity clays (i.e. CL-ML soils).

Foster and Fell (1999) suggested that $D_{15 \mathrm{~b}} / d_{85}$ for group I base soils is between $6 \cdot 4$ and $13 \cdot 5$. Similarly, Shourijeh and Soroush (2009) reported that $D_{15 \mathrm{~b}} / d_{85}$ is generally in the range from 7 to $13 \cdot 5$, although it may be as high as 27 .

\subsubsection{Variation of $D_{15 \mathrm{~b}}$ with $d_{85}$}

For 166 group I soils, the frequency distribution of $d_{85}$ is illustrated in Figure 1(a). For base soils in this group, $F_{\mathrm{c}} \geq 85 \%$, thus $d_{85} \leq 0.075 \mathrm{~mm}$. The average $d_{85}$ of the data was found to be $0.039 \mathrm{~mm}$, which corresponds to the mean dimension of silt-sized particles (i.e. $5-75 \mu \mathrm{m})$. While $64 \%$ of the data (107 soils) have $d_{85}$ in the range $0.02-0.05 \mathrm{~mm}$, only one base soil has a $d_{85}$ less than $0.01 \mathrm{~mm}$. Overall, concerning $d_{85}$, the data are normally distributed, covering the entire spectrum of group I base soils.

The distribution of $D_{15}$ b, shown in Figure 1(b), implies that $92 \%$ of the data (152 soils) have $D_{15 \mathrm{~b}}<0.6 \mathrm{~mm}$. The single $D_{15 \mathrm{~b}}$ higher than $0.9 \mathrm{~mm}$ may be regarded as an outlier, and will be cautiously dealt with (or removed) in further considerations. It is worth noting that only five of the base soils (i.e. $3 \%$ of the data) have $D_{15 \mathrm{~b}}<0.2 \mathrm{~mm}$, thus complying well with design guide assertions that prohibit critical filters with a $D_{15 \mathrm{~b}}$ lower than $0.2 \mathrm{~mm}$ (Fell et al., 2015; ICOLD, 2017; USBR, 2011). Interestingly, the average $D_{15 \mathrm{~b}}$ for the reported data is $0.41 \mathrm{~mm}$, which is quite close to $0.425 \mathrm{~mm}$, determined as the upper size limit of fine sands.

The frequency of $D_{15 \mathrm{~b}} / d_{85}$ observations for group I core soils $(N=166)$ is illustrated in Figure 1(c). $D_{15 \mathrm{~b}} / d_{85}$ is lower than 15 for $80 \%$ (i.e. 131) of the base soils, while $D_{15 \mathrm{~b}} / d_{85}<10$ for $48 \%$ of the data (79 soils). More precisely, 33\% of the data show $D_{15 \mathrm{~b}} / d_{85} \leq 9$, suggesting that $D_{15 \mathrm{~b}} / d_{85}=9$ may be unsafe in providing no erosion for some base (core) soils. In addition, $3 \%$ of the data (five base soils) show inordinately low $D_{15 \mathrm{~b}} / d_{85}$ values of $<5$. For four base soils (around $2 \%$ of the data), $D_{15 \mathrm{~b}} / d_{85}$ is in excess of 30 , and these data were omitted from further analysis.

The plot of $D_{15 \mathrm{~b}}$ against $d_{85}$ for group I base soils is illustrated in Figure 2. Accordingly, 97\% of the data (160 base soils) have
$D_{15 \mathrm{~b}} / d_{85}$ values between 4 and 30 . Evaluation of the data reveals that, for $d_{85} \geq 0.04 \mathrm{~mm}, D_{15 \mathrm{~b}} / d_{85}$ is lower than 13.5 (except for one base soil). In addition, it is implicitly discernible that an arbitrary $D_{15 \mathrm{~b}}$ is associated with a variety of $d_{85}$ sizes. These observations imply that (a) $D_{15 \mathrm{~b}} / d_{85}$ is predominantly influenced by $d_{85}$ (i.e. the denominator), thus an increase in $D_{15 \mathrm{~b}} / d_{85}$ is not essentially related to higher $D_{15 \mathrm{~b}}$, but rather controlled by a lower $d_{85}$ and $(b)$ base soil characteristics other than $d_{85}$ prominently influence filtration processes.

\subsubsection{Clay content and silt content}

The fines content $\left(F_{\mathrm{c}}\right)$ of base soils comprises clay $\left(C_{\mathrm{c}}=\right.$ percentage passing $\left.5 \mu \mathrm{m}\right)$ and silt $\left(M_{\mathrm{c}}=\right.$ percentage between $5 \mu \mathrm{m}$ and $75 \mu \mathrm{m})$ fractions; that is, $F_{\mathrm{c}}=C_{\mathrm{c}}+M_{\mathrm{c}}$. As shown in Figure 1(d), $C_{\mathrm{c}}$ shows a fairly normal distribution for group I base soils, with average of $41 \cdot 8 \%$. In addition, $69 \%$ of the data (114 soils) have $30 \% \leq C_{\mathrm{c}}<60 \%$ and hence few of the base soils in the data base are rich in clay or full of silt. Figure 3 illustrates the variation of $D_{15 \mathrm{~b}} / d_{85}$ with $C_{\mathrm{c}}$. Accordingly, $83 \%$ of soils with $C_{\mathrm{c}} \geq 40 \%$ have $D_{15 \mathrm{~b}} / d_{85}>9$ whereas, for $C_{\mathrm{c}}<40 \%, 52 \%$ of the data plot below $D_{15 \mathrm{~b}} / d_{85}=9$. Previous studies imply that clay content significantly influences the filtration behaviour of fine silts and clays (Delgado Ramos et al., 2006; Foster and Fell, 1999; Shourijeh and Soroush, 2009) and contemporary investigations on soil erosion characteristics have revealed that an increase in clay content reduces soil erodibility (Hanson et al., 2010; Wan and Fell, 2004). It should be noted that an increase in $C_{\mathrm{c}}$ is associated with a finer gradation, possessing a smaller $d_{85}$ and, intuitively, a higher $D_{15 \mathrm{~b}} / d_{85}$. In other words, soils with higher $C_{\mathrm{c}}$ do not essentially reflect a coarser $D_{15 \mathrm{~b}}$, yet their cohesive bonds and relative erosion resistance leads to a median $D_{15 \mathrm{~b}}$, which, in combination with their tiny $d_{85}$, leads to a high value of $D_{15 \mathrm{~b}} / d_{85}$.

Figure 4 shows the variation of $D_{15 \mathrm{~b}} / d_{85}$ with silt content, $M_{\mathrm{c}}$ (= percentage between $5 \mu \mathrm{m}$ and $75 \mu \mathrm{m}$ ). Although not clearly distinct, there is an overall trend of decreasing $D_{15 \mathrm{~b}} / d_{85}$ with an increase in $M_{\mathrm{c}}$. This observation would be predictable by the trend of $D_{15 \mathrm{~b}} / d_{85}$ plotted against $C_{\mathrm{c}}$ (Figure 3). According to Figure $4,47 \%$ of base soils with $M_{\mathrm{c}} \geq 50 \%$ have $D_{15 \mathrm{~b}} / d_{85}<9$ whereas, for soils with $M_{\mathrm{c}}<50 \%, 79 \%$ plot above $D_{15 \mathrm{~b}} / d_{85}=9$.

Sherard et al. (1984) stipulate that retaining silt-sized particles is prerequisite to the successful filtration of fine silts and clays (i.e. group I base soils). However, recent developments in soil erodibility measurements indicate that silty soils are normally more erodible than clayey soils (Fell et al., 2013; Regazzoni et al., 2008). It may be envisaged that the erosion product of clayey soils is coarser than individual silts due to the cohesive bonds holding clay particles together (Locke, 2001). Delgado Ramos et al. (2012) reported NEF tests on clayey soils with aluminium sulfate as a 'coagulating' additive: 'as expected the aluminium sulfate increased floc size and thereby increased filter size' (ICOLD, 2017: p. 169). 
Geotechnical Engineering

Volume 171 Issue GE3
A parametric database study of

no-erosion filter tests

Tabatabaie Shourijeh, Soroush, Shams Molavi

and Ramezani Fouladi

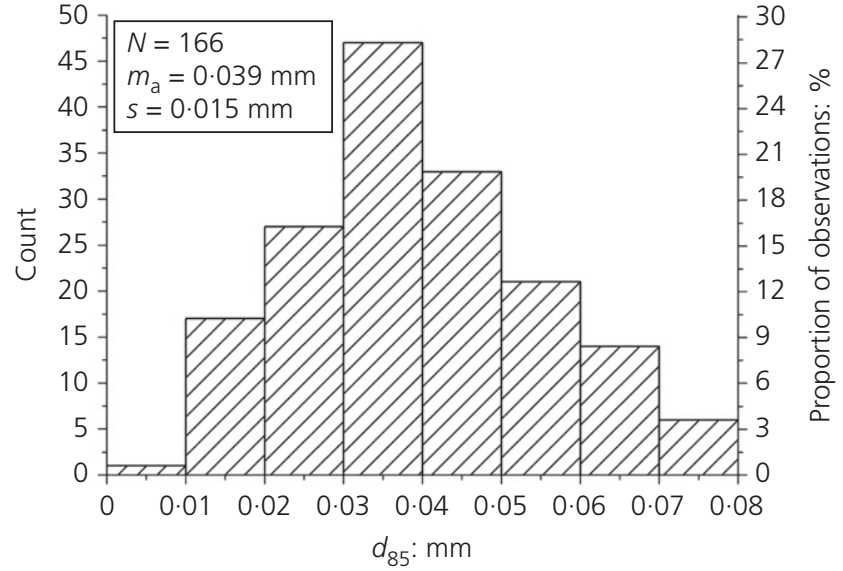

(a)

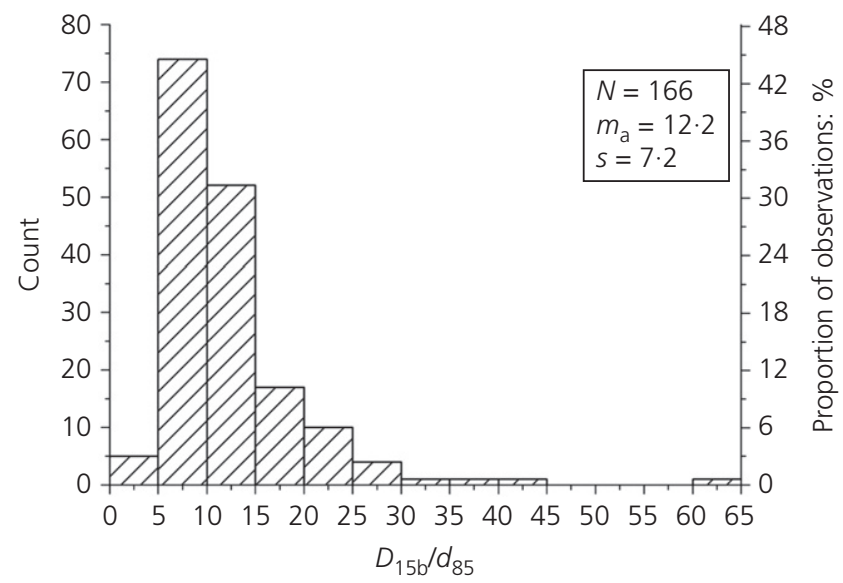

(c)

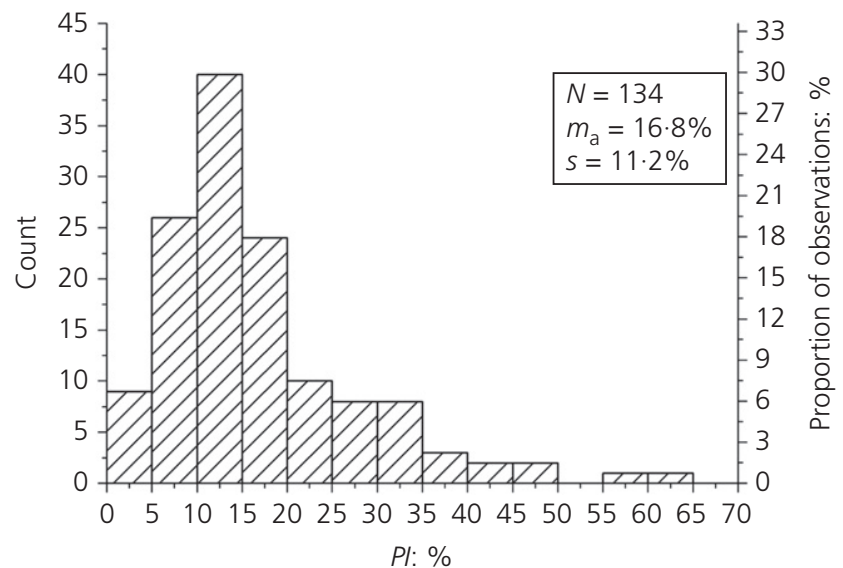

(e)

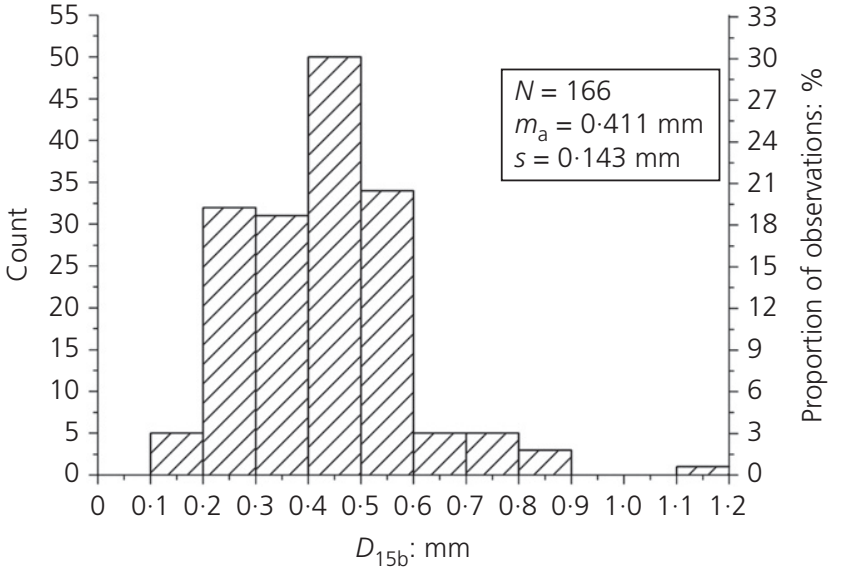

(b)

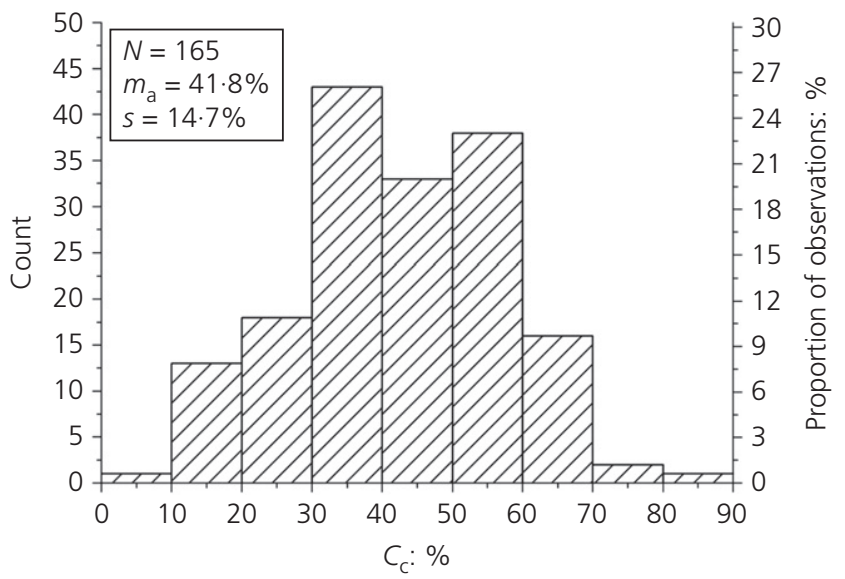

(d)

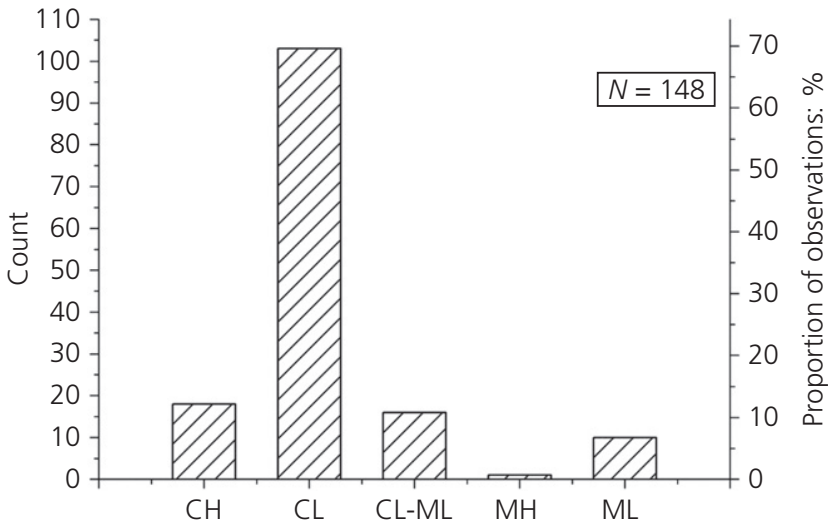

(f)

Figure 1. Frequency variations (histograms) of (a) $d_{85}$, (b) $D_{15 \mathrm{~b}}$, (c) $D_{15 \mathrm{~b}} / d_{85}$, (d) $C_{\mathrm{c}}$ and (e) PI and (f) bar chart of soil classification (USCS) for group I base soils ( $m_{a}$, arithmetic mean; $N$, number of data points; $s$, standard deviation)

\subsubsection{PI}

The variation in PI for 134 group I base soils is illustrated in Figure 1(e). This plot shows that $74 \%$ of the data (99 base soils) have $\mathrm{PI}<20 \%$, reflecting the average PI routinely encountered in clay/silt mixtures originating mainly from sedimentary environments. Such soils are abundantly available in many areas worldwide for use as core materials in embankment dams. Core soils at both ends of the PI variation (i.e. 


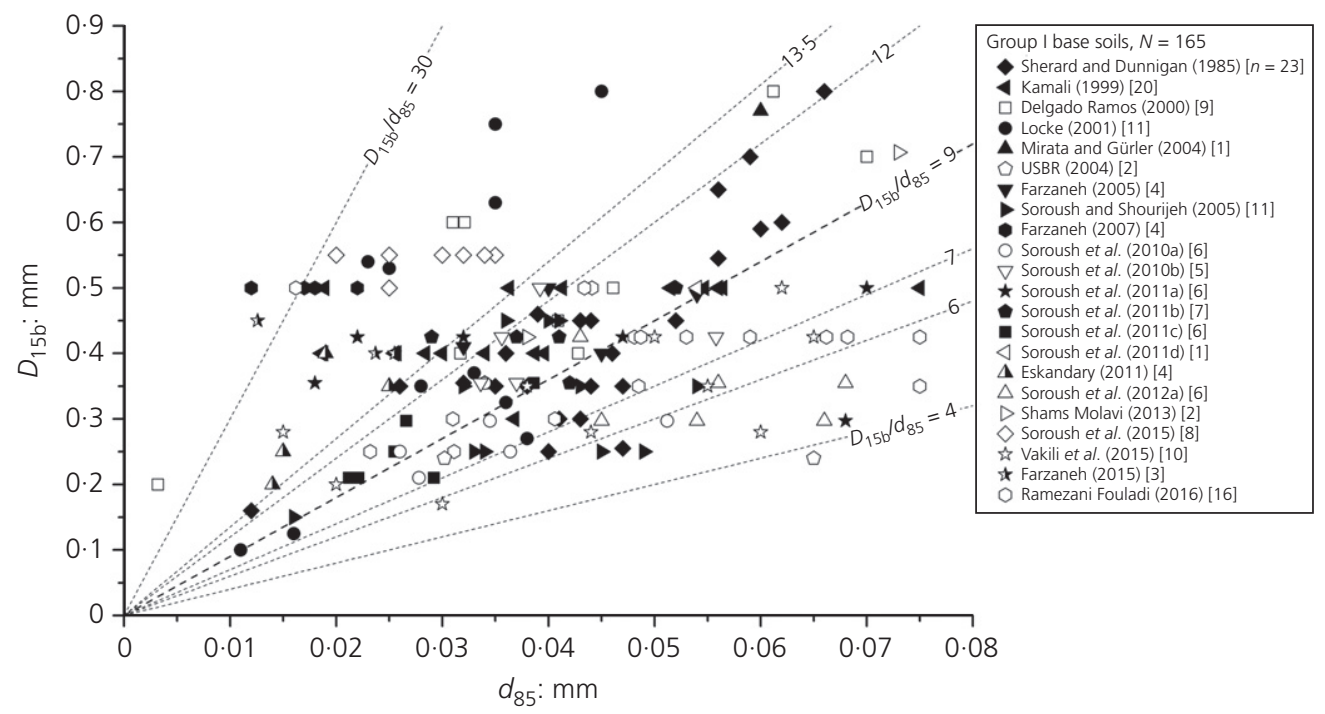

Figure 2. Variation of $D_{15 b}$ with respect to $d_{85}$ for group I base soils; $N$ (number of data points) $=165 ; n$, number of data points per reference

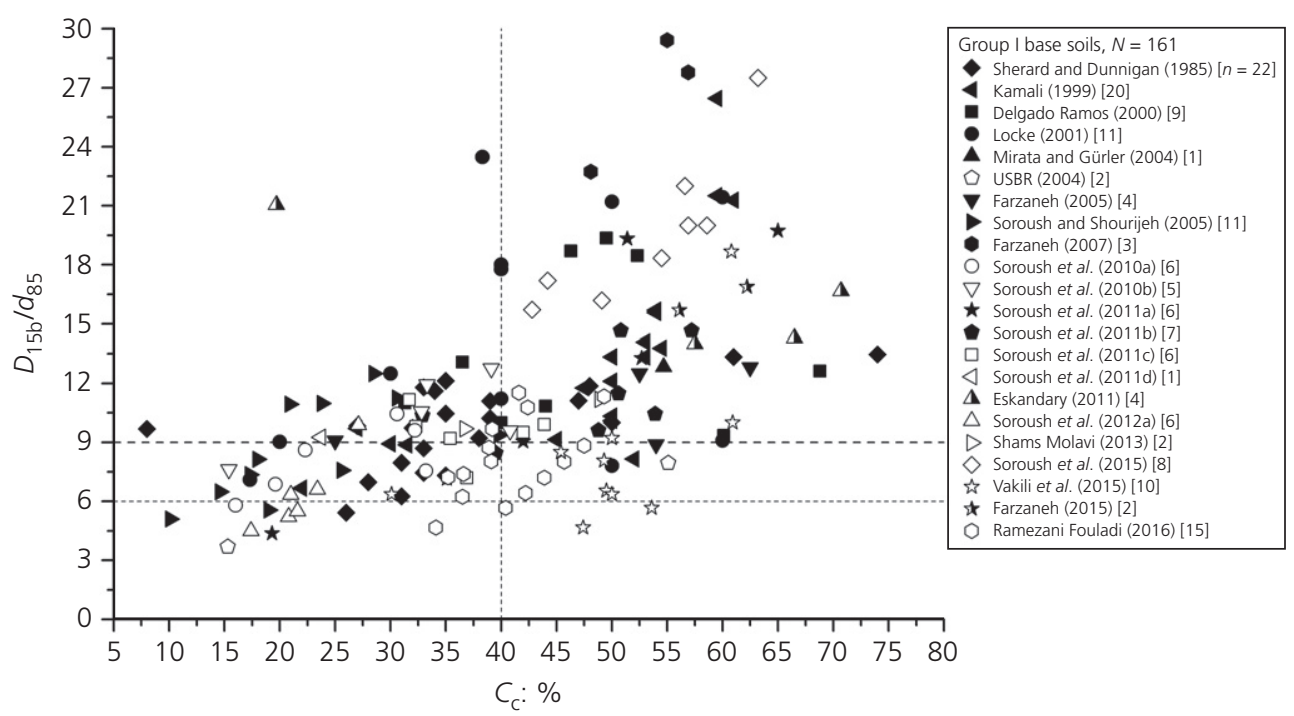

Figure 3. Variation of $D_{15 b} / d_{85}$ with clay content, $C_{c}$, for group I base soils $(N=161)$

possessing very high or very low PI) are infrequent: only two soils have PI $>50 \%$ and about $7 \%$ (nine soils) have $\mathrm{PI}<5 \%$. Pursuing this a step further, the variations in base soil category defined according to the USCS are shown in Figure 1(f). For the group I base soils with available USCS information $(N=148), 12 \%$ are $\mathrm{CH}, 70 \%$ are $\mathrm{CL}, 11 \%$ are CL-ML and $8 \%$ are ML. The MH type is extremely uncommon, with only one representative. The populations of soil categories represent the actual domain of soil classes encountered in embankment dams. On this subject, comprehensive statistical studies by Foster et al. (1998) revealed that (a) CL soils represented the majority of various soils types in embankment dam cores and (b) $34 \%$ of cores experiencing erosion damages/failures consisted of CL soils and 18\% were ML soils.

The variation of $D_{15 \mathrm{~b}} / d_{85}$ with respect to PI is plotted in Figure 5. The data are highly scattered, with no clear trend emerging. Nonetheless, the concentration of data with $D_{15 \mathrm{~b}} / d_{85}$ between 6 and 9 , or even with $D_{15 \mathrm{~b}} / d_{85}<6$, is much higher where $\mathrm{PI}<10 \%$. A decrease in PI generally leads to higher soil erodibility (Hanson et al., 2010; Wan and Fell, 2004), conceivably demanding finer filters. 


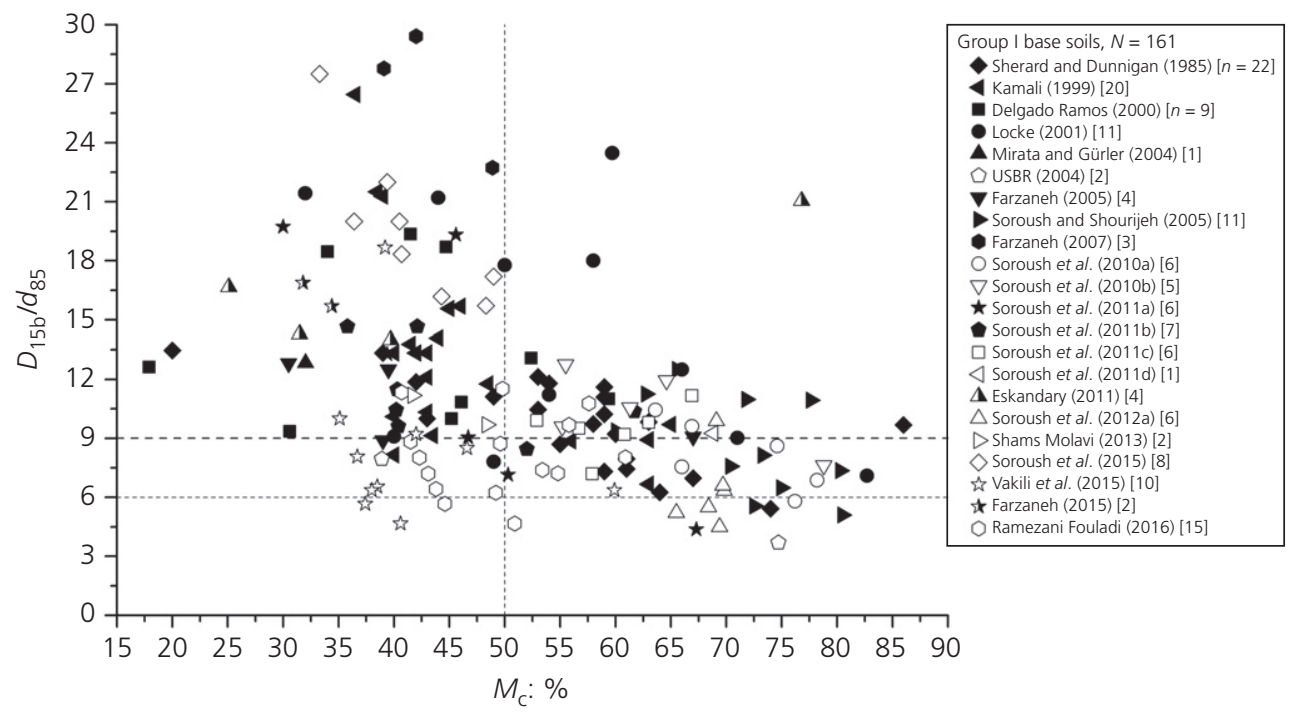

Figure 4. Variation of $D_{15 \mathrm{~b}} / d_{85}$ with silt content, $M_{\mathrm{c}}$, for group I base soils $(N=161)$

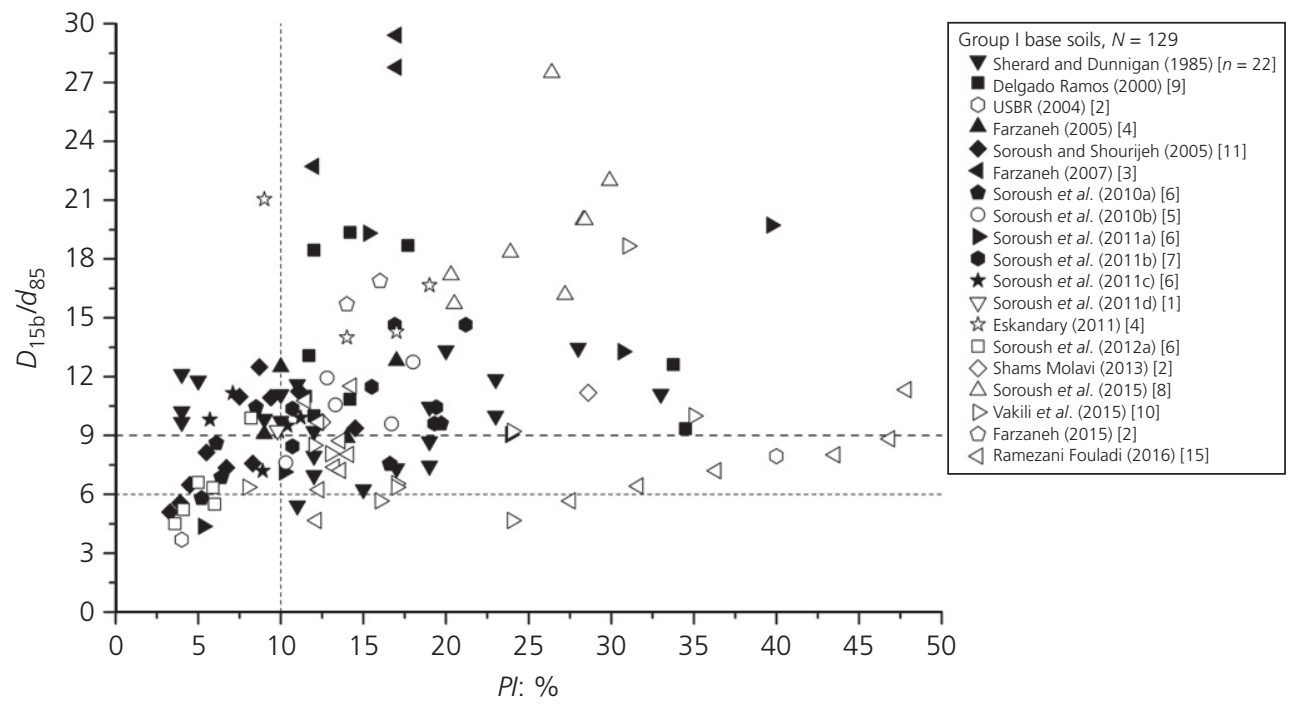

Figure 5. Variation of $D_{15 \mathrm{~b}} / d_{85}$ with PI for group I base soils $(N=129)$

Delgado Ramos et al. (2012) asserted that $D_{15 \mathrm{~b}}$ decreases as PI increases, and attributed this conclusion to the fact that soils with higher PI are generally finer, hence having a smaller $d_{85}$ which requires a finer filter. Such performance was not observed and deduced for the data studied in the current work. In brief, Delgado Ramos et al. (2012: p. 875) state that 'the base soil plasticity has influence in the boundary filter, but it is not as important as the base soil particle size distribution'.

\subsubsection{Activity ratio $\left(A_{\mathrm{r}}\right)$}

According to Fell et al. (2013: p. 358) 'The main physical parameters influencing the erosion of cohesive fine-grained soil are the particle size distribution (grain size), the clay fraction and the clay mineralogy'. Unfortunately, information concerning mineralogical compositions of the base soils is mostly unavailable in the database.

The activity ratio $\left(A_{\mathrm{r}}\right)$ may be considered as an indirect indicator of mineralogy for clay particles (Mitchell and Soga, 2005). The $A_{\mathrm{r}}$ is the ratio of PI (\%) to the percentage of particles finer than $2 \mu \mathrm{m}$. As shown in Figure 6, no perceptible relationship between $D_{15 \mathrm{~b}} / d_{85}$ and $A_{\mathrm{r}}-$ as a mineralogical descriptor - exists. Delgado Ramos et al. (2012) also inspected correlations between $D_{15 \mathrm{~b}}$ and clay mineralogy and found no significant relationship. 


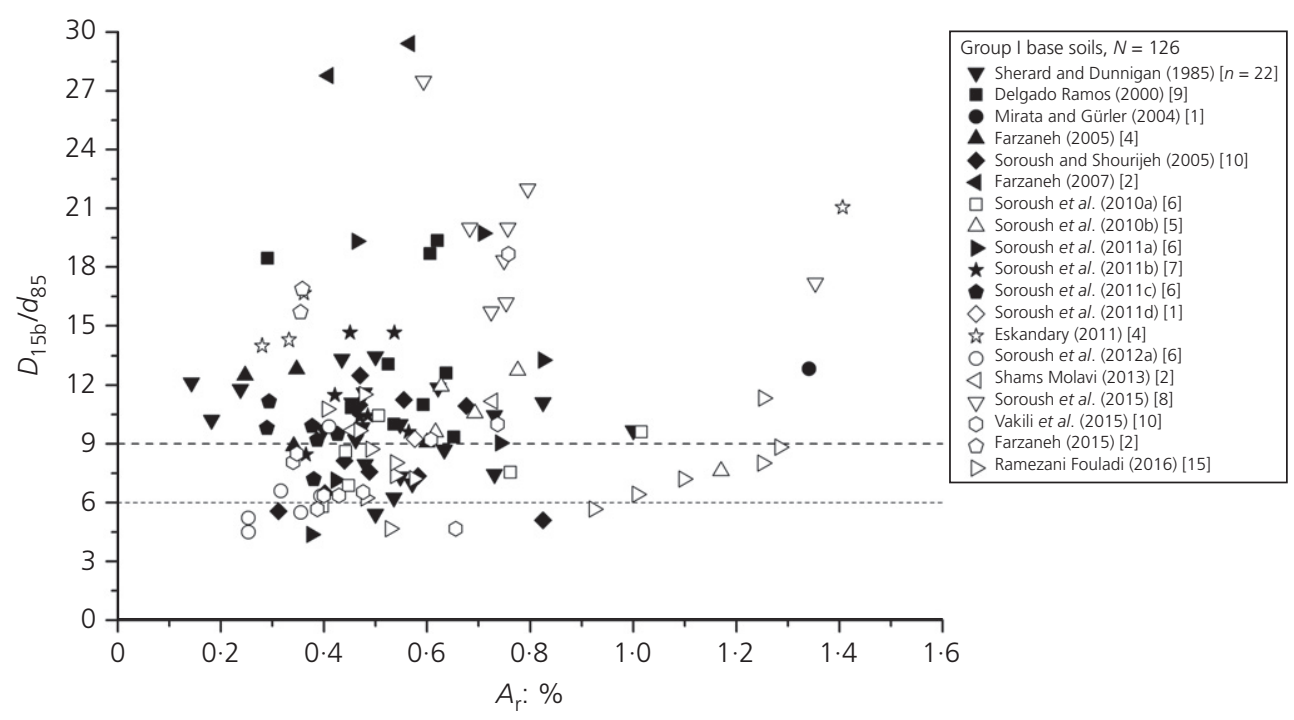

Figure 6. Variation of $D_{15 b} / d_{85}$ with activity ratio, $A_{r}$, for group I base soils $(N=126)$

\subsubsection{Dispersivity potential}

Dispersive erosion is an associated issue in the filtration of fine silts and clays (i.e. group I soils). This is of particular interest as various laboratory test procedures for determining dispersive soils, namely pinhole tests (ASTM D 4647 (ASTM, 2006a)), crumb tests (ASTM D 6572 (ASTM, 2006b)), double hydrometer testing (ASTM D 4221 (ASTM, 2011)) and chemical analysis (Sherard et al., 1976), give different results regarding the dispersivity of fine clays/silts (Fan and Kong, 2013).

Sherard and Dunnigan (1989) stated that $D_{15 \mathrm{~b}}$ is not related to a tendency for dispersive erosion. Contrary to this, filtration studies - specifically those containing NEF results - state that dispersive group I base soils require finer no-erosion filters, that is $D_{15 \mathrm{~b}}$ (Table 1). The criteria of $D_{15} \leq 6.4 d_{85}$ and $D_{15} \leq 6 \cdot 5 d_{85}$ have been recommended by Foster and Fell (1999) and USBR (2011), respectively, whereas Shourijeh and Soroush (2009) suggested $D_{15} \leq 7 \cdot 5 d_{85}$. More recently, Fell et al. (2015) proposed even finer filters for dispersive group I soils complying with $D_{15} \leq 6 d_{85}$ and, through elaborate NEF tests, Vakili et al. (2015) advised $D_{15} \leq 5 \cdot 5 d_{85}$.

In the database under study, information concerning the dispersive tendency of base soils is limited. Having said that, Figure 7 illustrates the variation of $D_{15 \mathrm{~b}} / d_{85}$ with dispersion percentage (measured by double hydrometer tests) for group I base soils. From the highly scattered data, a general trend of decreasing $D_{15 \mathrm{~b}} / d_{85}$ with an increase in dispersion percentage is weakly discernible. Both moderately dispersive (dispersion $=$ $30-50 \%$ ) and highly dispersive (dispersion $>50 \%$ ) soils (Bell and Maud, 1994) may require filters significantly finer than $D_{15 \mathrm{~b}}=9 d_{85}$. As shown in Figure 7, the criteria of $D_{15 \mathrm{~b}} \leq 6 d_{85}$ and $D_{15 \mathrm{~b}} \leq 5 \cdot 5 d_{85}$ are very close and respectively correspond to no erosion for $94 \%$ and $96 \%$ of the data. The variation of $D_{15 \mathrm{~b}}$ with $d_{85}$ for highly dispersive soils (pinhole classification D1 or D2) is shown in Figure 8. The limited data suggest that while $D_{15 \mathrm{~b}} / d_{85} \leq 9$ is fairly safe in most cases, $D_{15 \mathrm{~b}} / d_{85} \leq 6$ assures no erosion for all results.

\subsection{Base soil group II: sandy silts and clays}

Core soils with $35 \% \leq F_{\mathrm{c}}<85 \%$ are designated as group II (Table 1). In the original categorisation of Sherard and Dunnigan $(1985,1989)$, base soils with $40 \% \leq F_{\mathrm{c}}<85 \%$, were considered in group II, for which the experimentally defined $D_{15 \mathrm{~b}}$ generally ranged from 0.7 to $1.5 \mathrm{~mm}$ and no relation between $D_{15 \mathrm{~b}}$ and the base soils' gradations characteristics (i.e. $d_{85}$ ) was found. Additionally, Sherard and Dunnigan (1989) claimed that base soils with $35-40 \%$ fines content have filtration behaviours similar to group II base soils, in so far as 'the filter boundary $D_{15 \mathrm{~b}}$ is of the order of $0.8-1.5 \mathrm{~mm}$, independent of the $d_{85}$ size' (Sherard and Dunnigan, 1989: p. 943). Subsequent research by Foster and Fell (1999) revealed that base soils with $F_{\mathrm{c}}=35-40 \%$ are better considered in group II, and this notion has since been implemented in some filter criteria (Fell et al., 2015; Shourijeh and Soroush, 2009). Furthermore, Foster and Fell (1999) reported $D_{15 \mathrm{~b}}=0 \cdot 7-1 \cdot 7 \mathrm{~mm}$ for group II, irrespective of $d_{85}$.

\subsubsection{Variation of $D_{15 \mathrm{~b}}$ with $d_{85}$}

As illustrated in Figure 9(a), the frequency variation of $d_{85}$ for group II base soils is highly biased to finer/smaller $d_{85}$ sizes (note that the standard deviation $(s)$ is higher than arithmetic mean $\left.\left(m_{\mathrm{a}}\right)\right)$. This means that, that in dealing with group II base soils, designers/specialists were commonly inclined towards selecting finer base soil gradations close to group I. 


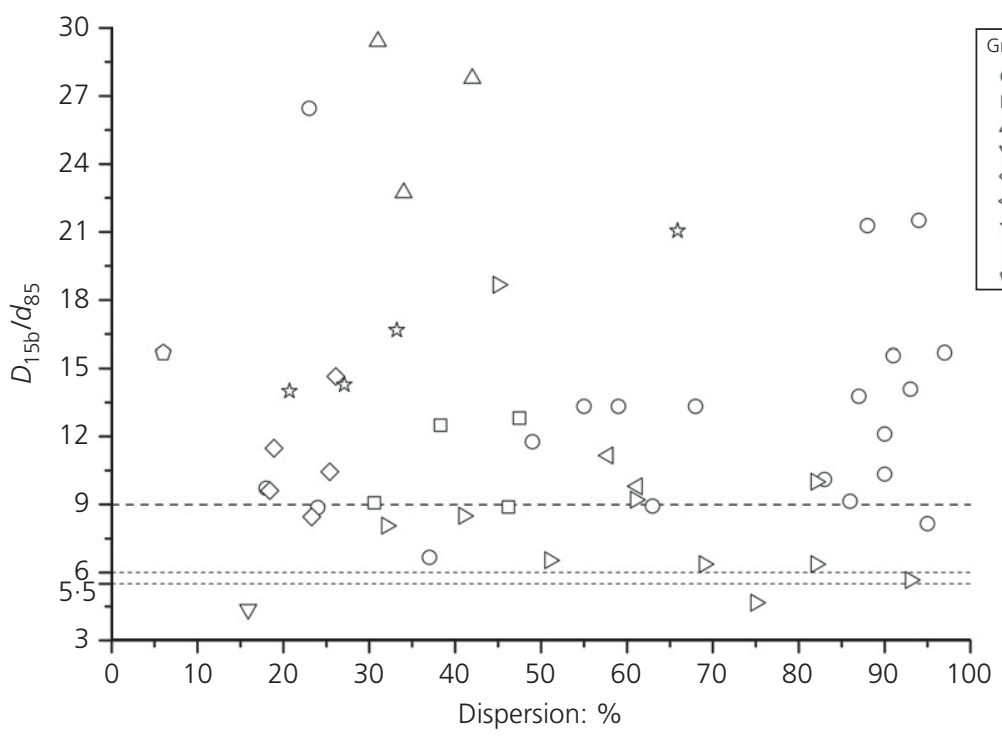

Figure 7. Variation of $D_{15 \mathrm{~b}} / d_{85}$ with dispersion percentage for group I base soils $(N=50)$

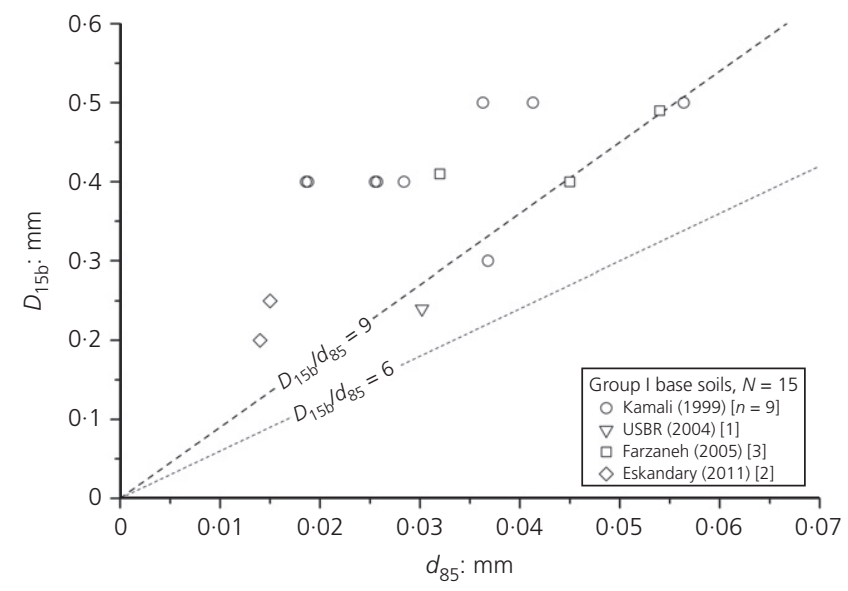

Figure 8. Variation of $D_{15 \mathrm{~b}}$ with $d_{85}$ for highly dispersive (pinhole classification D1 or D2) group I base soils $(N=15)$

Concerning this idea, USBR (2011: p. 72) asserts that if the base soils fall within more than one category for new or existing dams, then generally use the finer side of the range of gradations'.

According to Figure 9(b), $D_{15 \mathrm{~b}}$ for group II base soils is generally $(96 \%$ of the data) lower than $1.6 \mathrm{~mm}$. Moreover, $48 \%$ of the data (44 base soils) have $D_{15 \mathrm{~b}}<0.8 \mathrm{~mm}$. There is only one instance with $D_{15 \mathrm{~b}}$ higher than $2.2 \mathrm{~mm}$, and this outlier is not included in further analyses.

The variation of $D_{15 \mathrm{~b}}$ with $d_{85}$ for 91 group II base soils is shown in Figure 10. No clear trend between $D_{15 \mathrm{~b}}$ and $d_{85}$ can be discerned but, in general, finer base soils (i.e. lower $d_{85}$ ) require a smaller $D_{15 \mathrm{~b}}$. Inspection of Figure 10 implies that
$66 \%$ of the data have $D_{15 \mathrm{~b}} \geq 0.7 \mathrm{~mm}$ and, where $d_{85} \geq 0.3 \mathrm{~mm}$, the criterion of $D_{15 \mathrm{~b}}=0.7 \mathrm{~mm}$ may be considered safe overall in ensuring no erosion. Of note, some data points presented in Figure 10, particularly those with $D_{15 \mathrm{~b}}<0.7 \mathrm{~mm}$, are drawn from soils with a dispersive tendency. The filtration properties of such group II base soils are studied separately in forthcoming sections.

\subsubsection{Fines content}

Figure 9(c) illustrates that $F_{\mathrm{c}}$ observations for group II base soils are inclined to higher values: $57 \%$ of the data (52 soils) have $F_{\mathrm{c}}<75 \%$, while $29 \%$ (27 soils) have $F_{\mathrm{c}} \geq 80 \%$. This is not surprising recalling the $d_{85}$ variation (Figure 9(a)) and noting that, logically, soils on the finer edges of core material ranges are chosen for NEF testing and filter substantiation (USBR, 2011).

Figure 11 illustrates the variation of $D_{15 \mathrm{~b}}$ with $F_{\mathrm{c}}$ (i.e. percentage $<75 \mu \mathrm{m}$ ) for group II base soils. An overall trend of decreasing $D_{15 \mathrm{~b}}$ with increasing $F_{\mathrm{c}}$ is shown, and this trend is more pronounced for $F_{\mathrm{c}}>75 \%$. It is intuitively inferable that finer base soils would most likely require finer filters. As noted by Shourijeh and Soroush (2009), group II base soils with a high fines content impart behaviours similar to group I bases; hence, $D_{15 \mathrm{~b}} / d_{85}$ might better represent their no-erosion boundary. Subsequently, Shourijeh and Soroush proposed that, for group II base soils with $F_{\mathrm{c}} \geq 80 \%, D_{15 \mathrm{~b}}$ should be selected as $0.7 \mathrm{~mm}$ or $6 \cdot 4 d_{85}$, whichever is the smaller.

A scatterplot of $D_{15 \mathrm{~b}} / d_{85}$ against $F_{\mathrm{c}}$ for group II base soils is shown in Figure 12. When $F_{\mathrm{c}}<80 \%$, almost all the data have $D_{15 \mathrm{~b}} / d_{85}<6 \cdot 4$. However, for $F_{\mathrm{c}} \geq 80 \%, D_{15 \mathrm{~b}} / d_{85}$ shows a drastically different range, from 1 to 13 . 


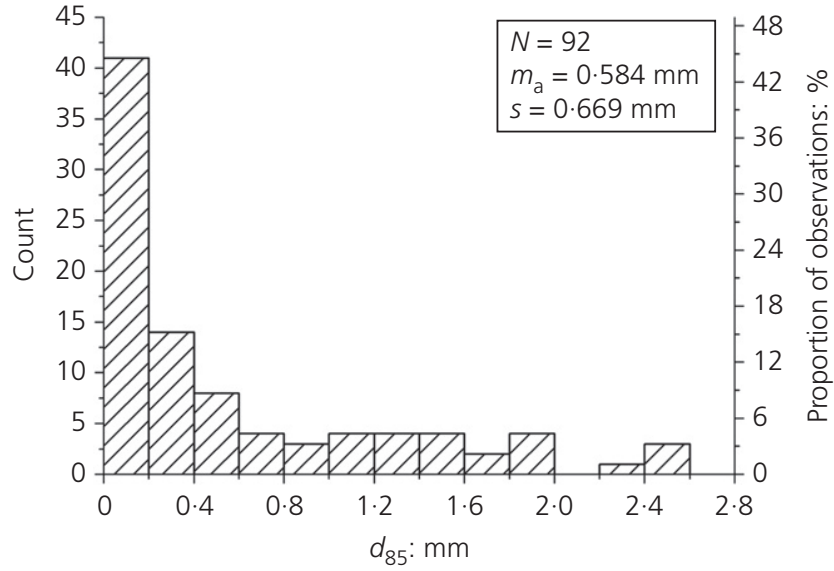

(a)

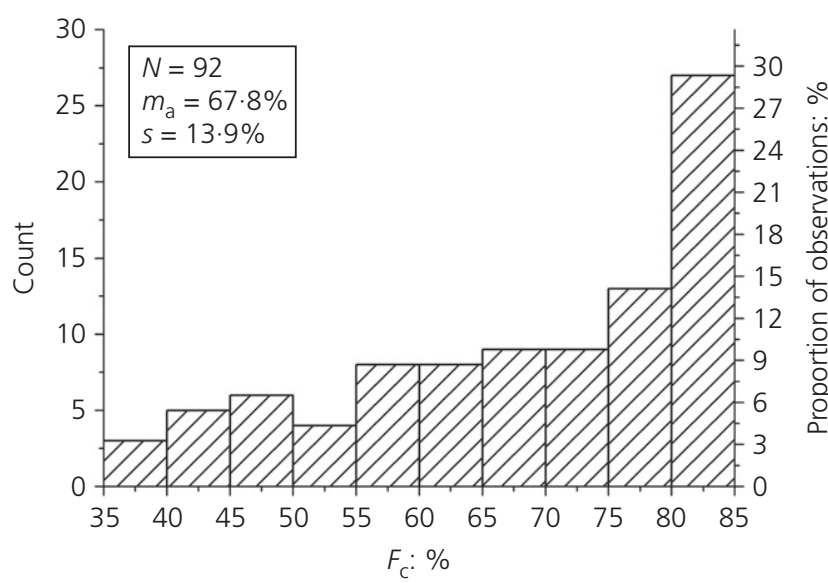

(c)

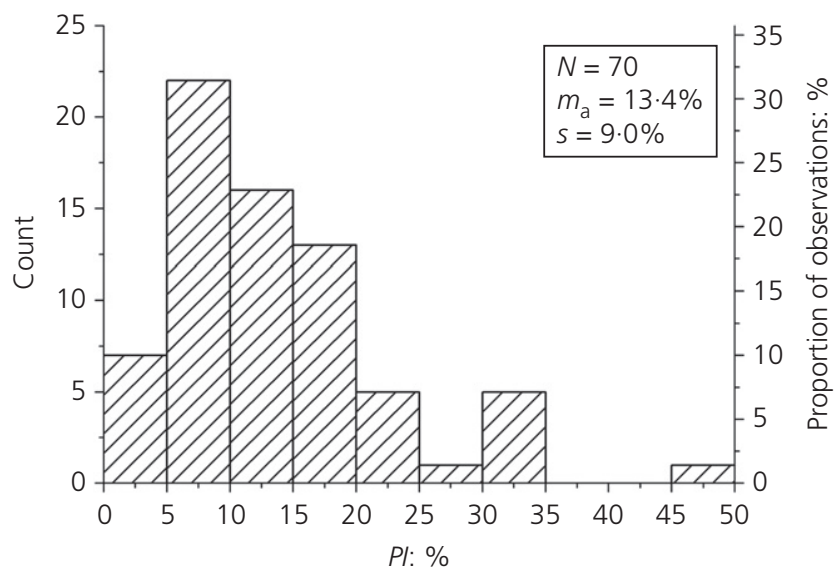

(e)

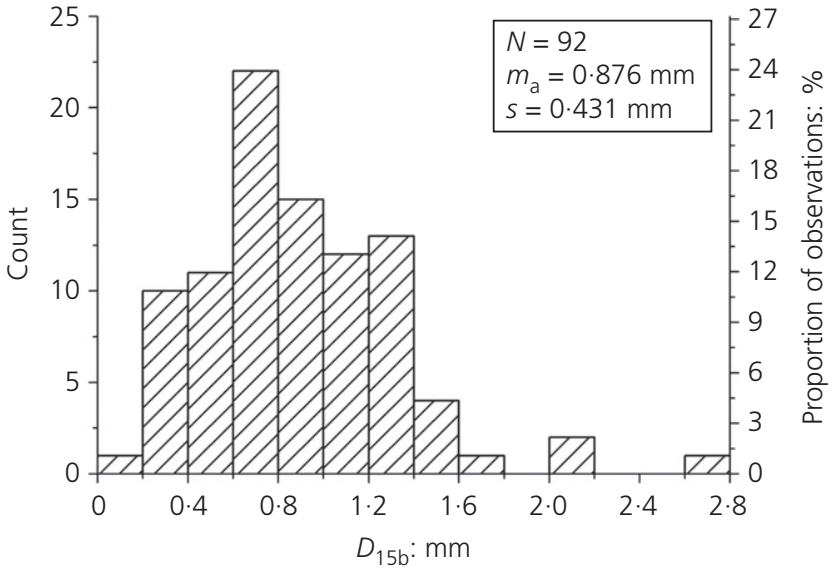

(b)

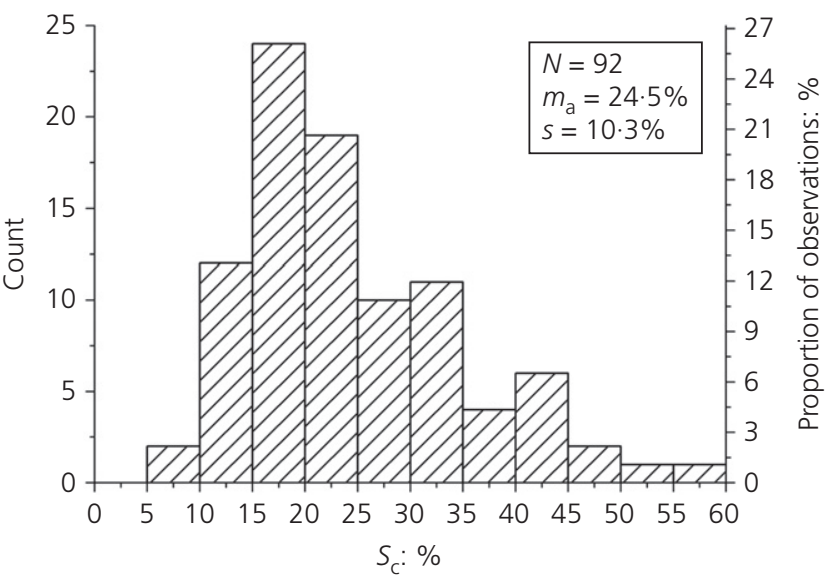

(d)

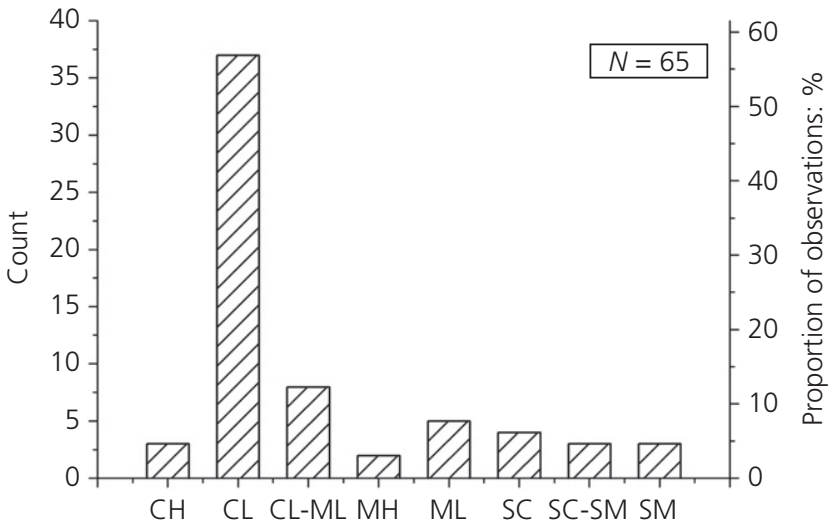

(f)

Figure 9. Frequency variations (histograms) of (a) $d_{85}$, (b) $D_{15 b}$, (c) $F_{c}$, (d) $S_{c}$ and (e) PI and (f) bar chart of soil classification (USCS) for group II base soils

Figure 13 shows the variation of $D_{15 \mathrm{~b}}$ against $d_{85}$ for group II base soils with $F_{\mathrm{c}} \geq 80 \%$. According to the figure, $D_{15 \mathrm{~b}}=0.7 \mathrm{~mm}$ is certainly unsafe and most base soils require finer no-erosion filters. Moreover, taking the minimum of $0.7 \mathrm{~mm}$ and $6.4 d_{85}$
(Table 1) is also inadequate for nearly half of the data. By disregarding allocated dispersive base soils (Figure 13), the newly suggested criterion of selecting $D_{15 \mathrm{~b}}$ as the minimum of $0.5 \mathrm{~mm}$ and $5 d_{85}$ is safe for $90 \%$ of base soils. At first glance, 


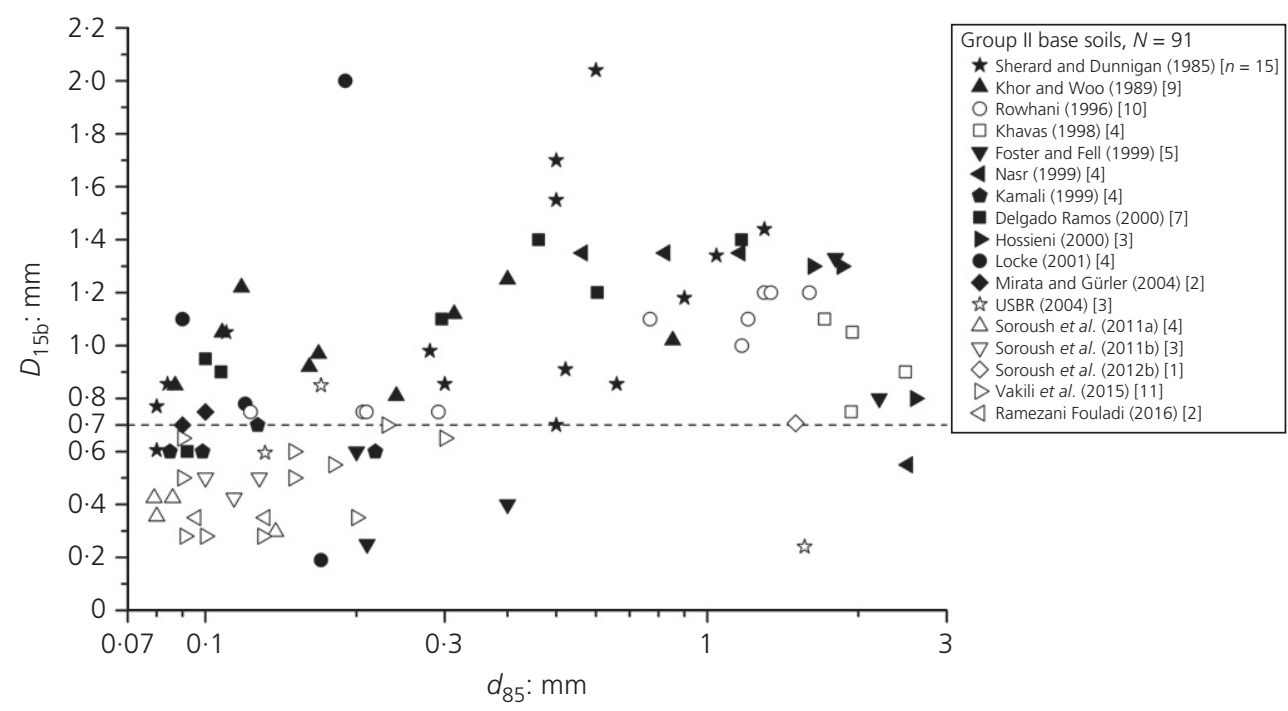

Figure 10. Variation of $D_{15 \mathrm{~b}}$ with $d_{85}$ for group II base soils $(N=91)$

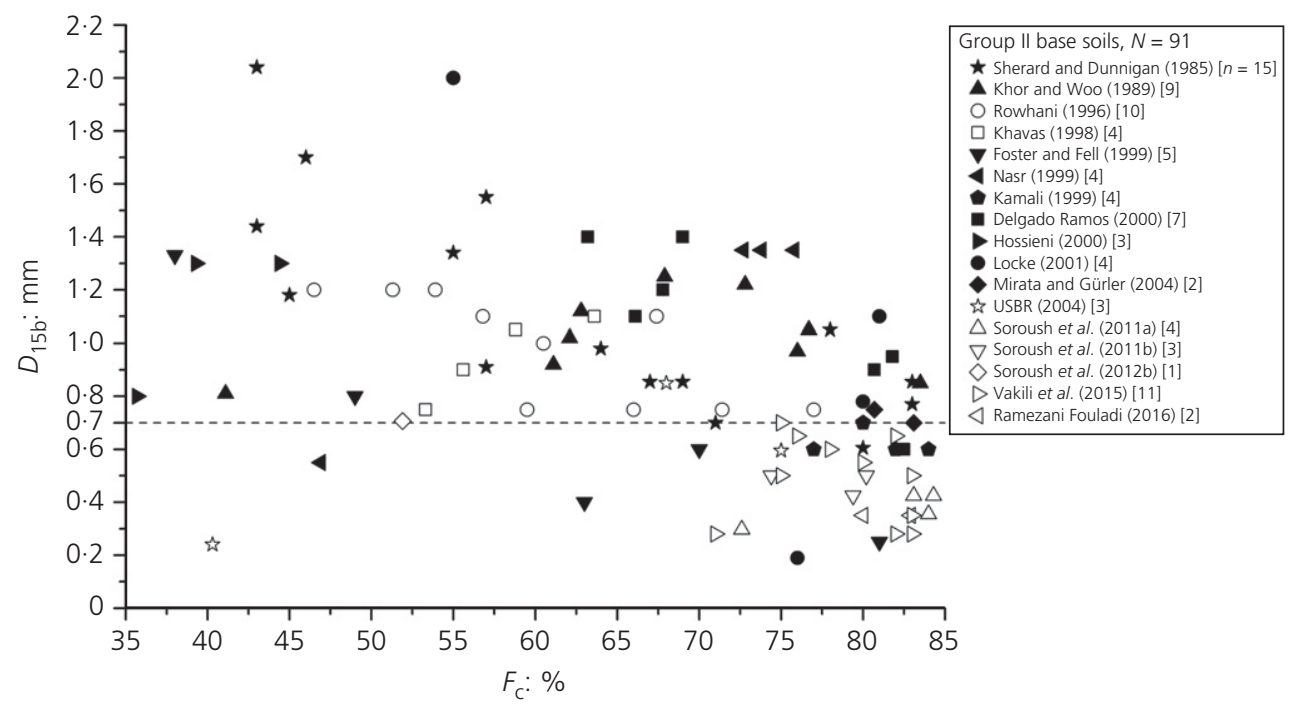

Figure 11. Variation of $D_{15 b}$ with fines content, $F_{c}$ for group II base soils $(N=91)$

$5 d_{85}$ may seem unduly conservative, yet group II base soils always have $d_{85} \geq 0.075 \mathrm{~mm}$; hence, the proposed criterion is in fact delineating a $D_{15 \mathrm{~b}}$ bounded between $0.375 \mathrm{~mm}$ and $0.5 \mathrm{~mm}$.

\subsubsection{Fine to medium sand content}

The variation of fine to medium sand content (i.e. percentage of particles between $75 \mu \mathrm{m}$ and $1.18 \mathrm{~mm}), S_{\mathrm{c}}$, for group II base soils is shown in Figure 9(d). The figure shows that $S_{\mathrm{c}}$ is normally distributed (particularly when compared with $F_{\mathrm{c}}$ ) in the range of $5 \%$ to $60 \%$, with $41 \%$ of the data (38 base soils) having $S_{\mathrm{c}}<20 \%$.

The variation of $D_{15 \mathrm{~b}}$ with $S_{\mathrm{c}}$ is presented in Figure 14: $D_{15 \mathrm{~b}}$ increases with an increase in $S_{\mathrm{c}}$ in so much as, for $S_{\mathrm{c}} \geq 30 \%$, the criterion of $D_{15 \mathrm{~b}}=0.7 \mathrm{~mm}$ ensures no erosion for $92 \%$ of the data. For base soils with $S_{\mathrm{c}} \geq 30 \%, F_{\mathrm{c}}$ is delimited between $36 \%$ and $68 \%$, suggesting that in the filtration of group II base soils, fine to medium sand particles play a more significant role as the fines content decreases. Continuingerosion filter tests carried out by Foster and Fell (1999) demonstrated that fine to medium sand particles in the base soil influence filtration and contribute to forming a selffiltration layer.

This analysis validates the proposition by Shourijeh and Soroush (2009) that group II base soils have diverse filtration behaviours depending on their fines content $\left(F_{\mathrm{c}}\right)$. The entire domain of group II core soils have $35 \% \leq F_{\mathrm{c}}<85 \%$. When 


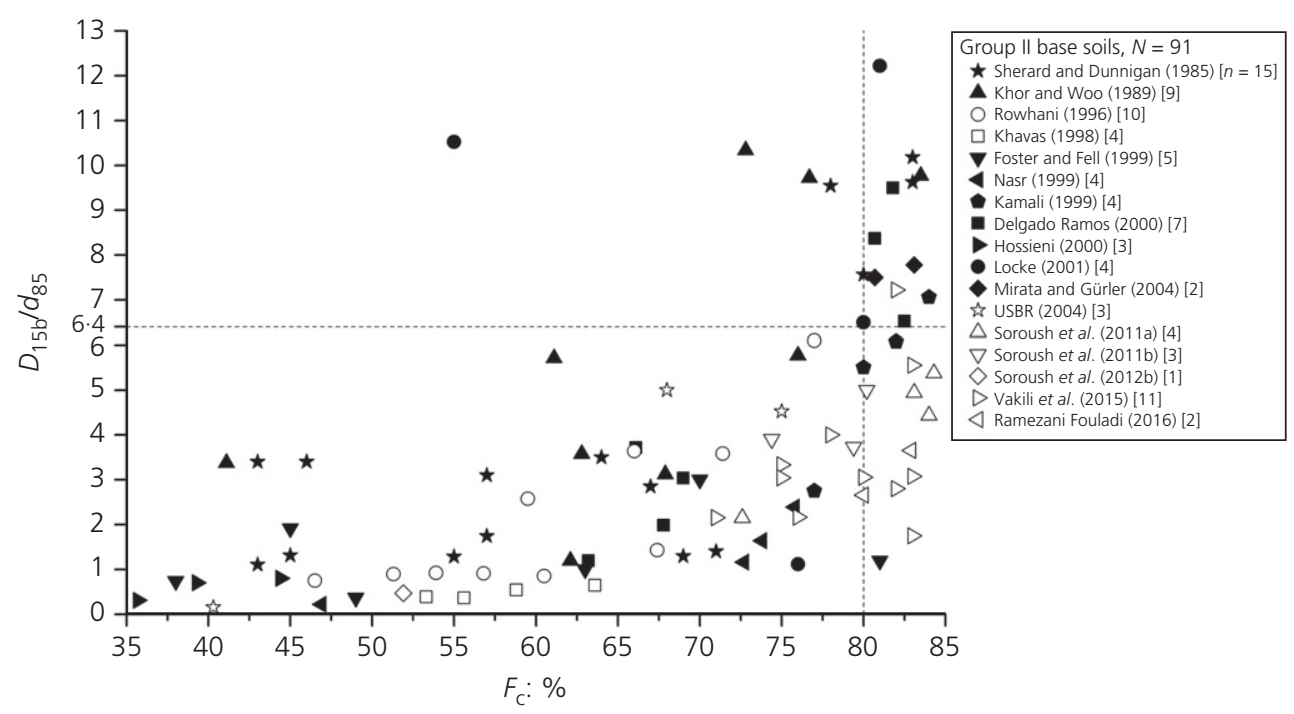

Figure 12. Variation of $D_{15 b} / d_{85}$ with fines content, $F_{c}$ for group II base soils $(N=92)$

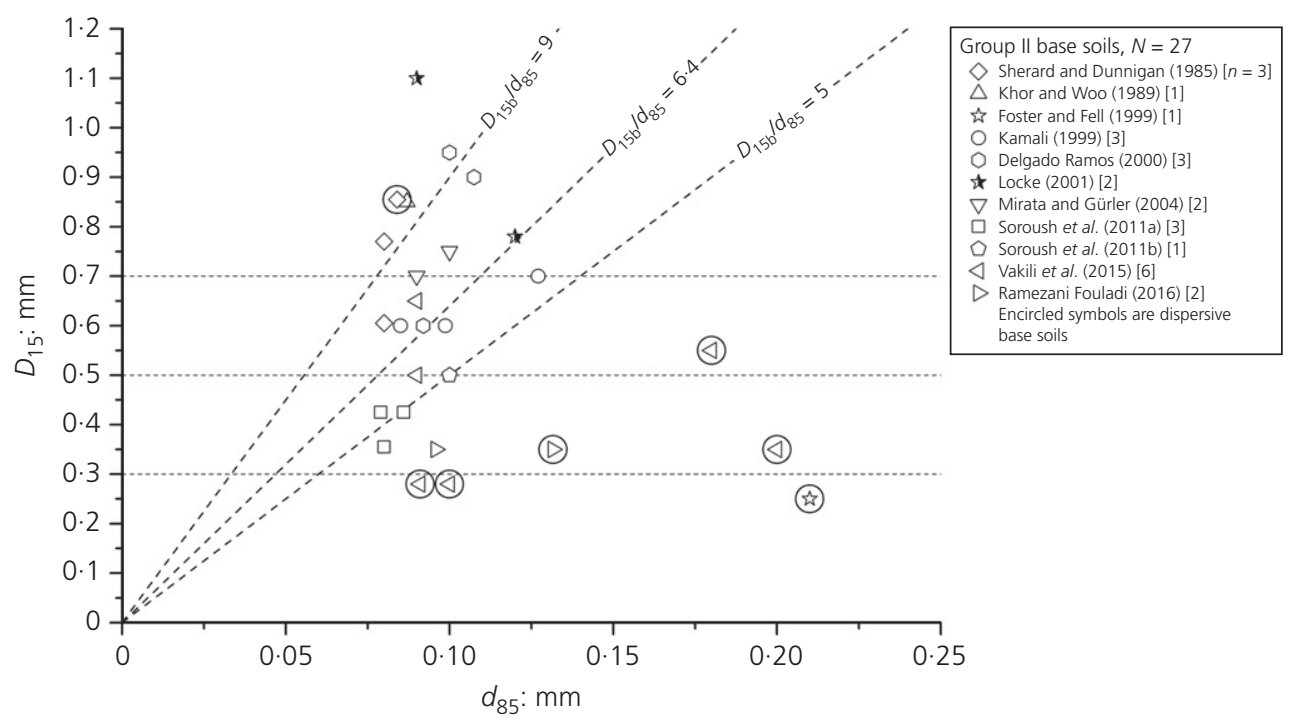

Figure 13. Variation of $D_{15 \mathrm{~b}}$ with $d_{85}$ for group II base soils with $F_{\mathrm{c}} \geq 80 \%(N=27)$

$F_{\mathrm{c}} \geq 80 \%$, base soils are close to group I and reflect similar filtration properties. For $65 \% \leq F_{\mathrm{c}}<80 \%$, fines are preponderant in the soil fabric and hence dominate filtration. In the case of coarser base soils with $35 \% \leq F_{\mathrm{c}}<65 \%$, fine to medium sand particles are ample and significantly influence filtration behaviour.

\subsubsection{PI}

From the PI frequency variation illustrated in Figure 9(e) it is apparent that group II base soils have lower PIs than group I soils due to their lower $F_{\mathrm{c}}$ and, in turn, higher $S_{\mathrm{c}}$. Moreover,
$83 \%$ of the data (note that $N=70$ ) have PI $<20 \%$, corresponding to lean clays/silts with sand.

Group II base soils with available USCS information $(N=65)$ are categorised in Figure 9(f). As anticipated from the possible base soils in this group (i.e. $F_{\mathrm{c}}=35-85 \%$ ), a variety of soil classifications are encountered, from high-plasticity clays $(\mathrm{CH})$ to cohesionless silty-sand soils (SM). Among the group II base soils, the most frequent classes are CL (57\%), CL-ML (12\%) and ML ( $8 \%$ ). The SC, SC-SM and SM groups combined represent $15 \%$ of the data. This further corroborates the notion 


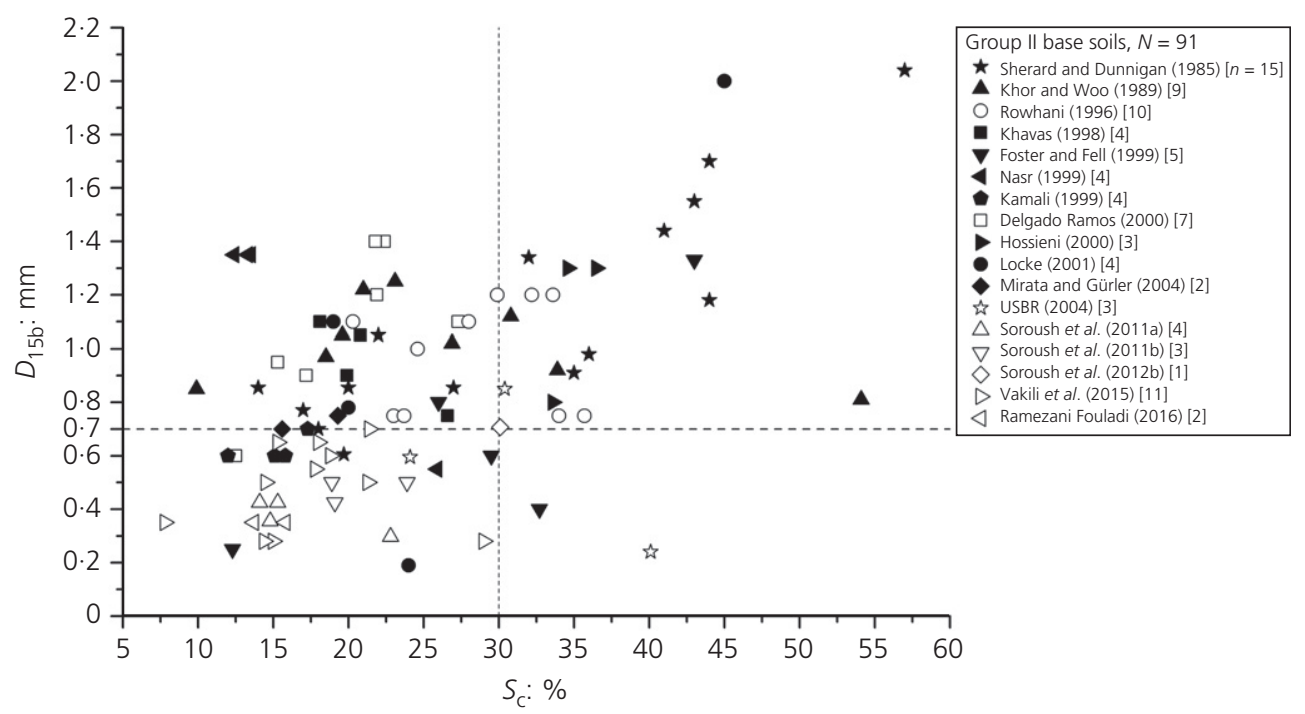

Figure 14. Variation of $D_{15 b}$ with fine to medium sand content, $S_{c}$, for group II base soils $(N=91)$

that NEF tests by researchers on group II base soils have been concentrated on finer soils close to group I.

Figure 15 shows the variation of $D_{15 \mathrm{~b}}$ with PI for group II base soils. Wherever the base soil was non-plastic, the PI was assumed to be $1 \%$ in order to avoid zero values. A clear relation between $D_{15 \mathrm{~b}}$ and PI cannot be recognised, but it is apparent that, with a decrease in PI, the number of data points with $D_{15 \mathrm{~b}}>0.7 \mathrm{~mm}$ increases. An increase in PI is associated with a finer gradation curve, possessing a higher $F_{\mathrm{c}}$, which requires a finer filter $\left(D_{15 \mathrm{~b}}\right)$. Note that, for sandy soils, an increase in PI is generally less influential in depleting erodibility in comparison with fine silts and clays (Fell et al., 2013).

\subsubsection{Dispersivity potential}

The filter design criteria shown in Table 1 all commonly state that for dispersive group II base soils it is safe to consider $D_{15 \mathrm{~b}} \leq 0.5 \mathrm{~mm}$. In Figure 13, dispersive group II base soils with $F_{\mathrm{c}} \geq 80 \%$ are indicated by encircled symbols. Obviously, $D_{15 \mathrm{~b}}=0.5 \mathrm{~mm}$ is not suitable for such soils, implying that $D_{15 \mathrm{~b}} \leq 0.3 \mathrm{~mm}$ would better ensure no erosion. Similarly, Vakili et al. (2015) suggested $D_{15 \mathrm{~b}} \leq 0 \cdot 28 \mathrm{~mm}$ for highly dispersive group II base soils.

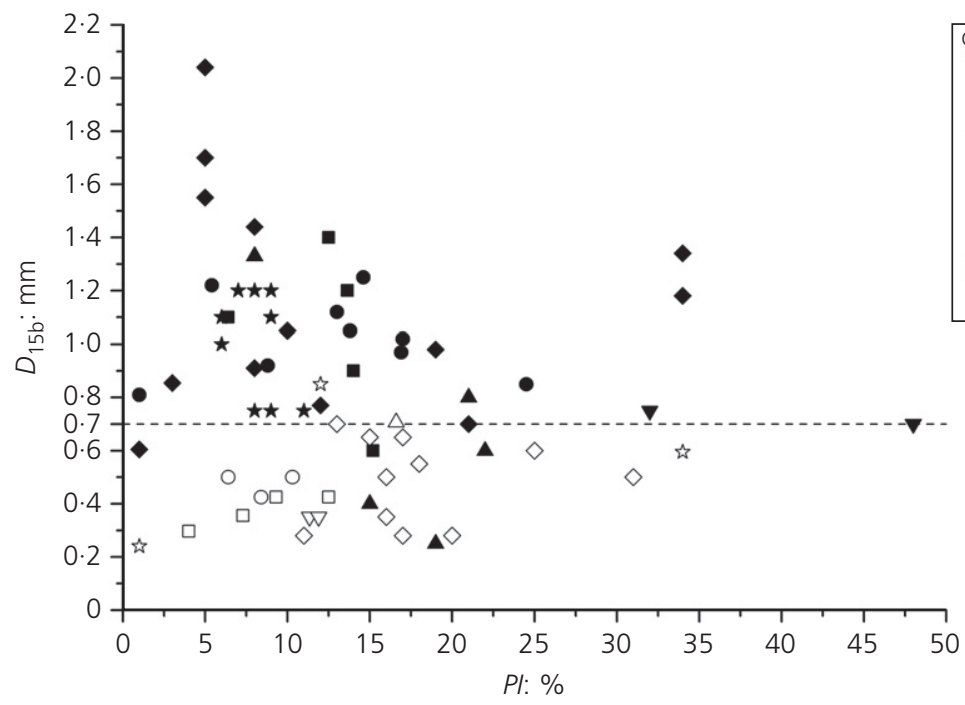

Figure 15. Variation of $D_{15 b}$ with PI for group II base soils $(N=69)$ 


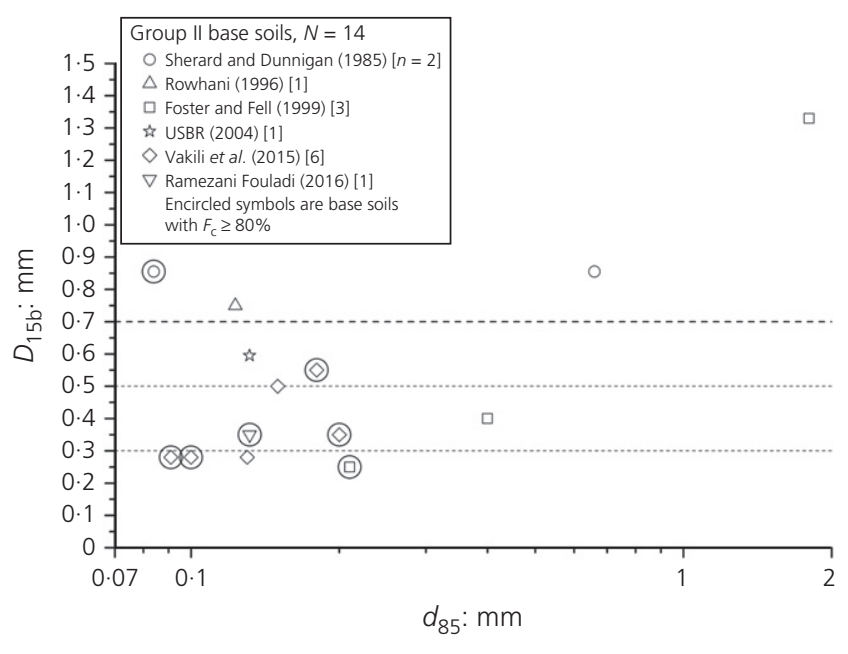

Figure 16. Variation of $D_{15 \mathrm{~b}}$ with $d_{85}$ for highly dispersive group II base soils $(N=14)$

Figure 16 illustrates the variation of $D_{15 \mathrm{~b}}$ with $d_{85}$ for all highly dispersive group II base soils. The data are very limited, especially when noting that $(a)$ half the base soils (seven out of 14) were analysed in Figure 13 , devoted to $F_{\mathrm{c}} \geq 80 \%$, and $(b)$ a unified approach for determining highly dispersive soils was not involved (i.e. defined by either pinhole or double hydrometer tests). Despite these setbacks, for highly dispersive group II base soils with $F_{\mathrm{c}}<80 \%$, the $D_{15 \mathrm{~b}} \leq 0.5 \mathrm{~mm}$ criterion may be considered adequate for $71 \%$ (five out of seven base soils) of the data.

\section{Summary and conclusions}

In spite of all advances in understanding internal erosion and piping for embankment dams, protective filters are commonly designed and substantiated implementing simple experimentally derived criteria. The critical filter design criteria listed in Table 1 were first introduced by Sherard and Dunnigan (1985) and still hold today, three decades after their initial presentation.

In this study, critical filter design criteria (Table 1) were revisited by investigating an extensive database of 258 group I and group II (i.e. $F_{\mathrm{c}} \geq 35 \%$ ) core (base) soils and their associated no-erosion filters. The main updates of the current investigation in comparison with the study reported by Shourijeh and Soroush (2009) are that the number of data incorporated was increased (258 instead of 152 previously analysed), specifically those concerning dispersive core (base) soils, and a more rigorous statistical/parametric analysis was applied to the database.

The database's salient feature is that it is collated entirely from NEF test results. The parametric study assessed the influences of various core soil parameters $\left(d_{85}\right.$, clay content $\left(C_{\mathrm{c}}\right)$, silt content $\left(M_{\mathrm{c}}\right)$, fines content $\left(F_{\mathrm{c}}\right)$, fine to medium sand content $\left(S_{\mathrm{c}}\right)$, PI, dispersivity) on experimentally determined values of
$D_{15 \text { b }}$ (the no-erosion boundary filter). The aforementioned parameters have complicated reciprocal interactions; that is, an increase in one results in the other's decline or increase. Translating their influences on NEF test results in a quantitative manner into simple/straightforward criteria and design rules would thus require utmost caution and precision. Therefore NEF test results should have the final say in filter design.

For group I cores $\left(F_{\mathrm{c}} \geq 85 \%\right)$, the main conclusions inferred from the parametric study are as follows.

- Soil particle size represented by $d_{85}$ is the most significant factor in filtration.

- Clay content $\left(C_{\mathrm{c}}\right)$ and PI positively affect filtration, while the activity ratio $\left(A_{\mathrm{r}}\right)$ seems ineffective.

- Soils with $d_{85}<0.04 \mathrm{~mm}$ or $C_{\mathrm{c}}>40 \%$ may reflect a high $D_{15 \mathrm{~b}} / d_{85}$ in NEF testing, yet this does not essentially mean a coarser filter (i.e. a higher $D_{15 \mathrm{~b}}$ ). In fact, $D_{15 \mathrm{~b}}$ for such soils falls in the general $D_{15 \mathrm{~b}}$ ranges observed for group I soils and hence the $D_{15} / d_{85} \leq 9$ criterion should not be relaxed.

- Base soils with a PI less than $10 \%$, or classified as ML/CL-ML, have comparatively low erosion resistance, thus accentuating the conservative $D_{15} / d_{85} \leq 6$ criterion.

- In the authors' opinion, soils having both PI $<10 \%$ and $d_{85}<0.04 \mathrm{~mm}$ are highly erodible and problematic in regard to filtration and require very careful filter design.

- When the soil is dispersive, the criterion of $D_{15} / d_{85} \leq 6$ is safe.

Regarding group II core soils $\left(35 \% \leq F_{\mathrm{c}}<85 \%\right)$, the following findings are presented.

- Filtration is dominantly controlled by the fines content, $F_{\mathrm{c}}$.

- When $F_{\mathrm{c}} \geq 80 \%$, the soil behaves essentially similar to group I base (core) soils and requires a comparatively fine no-erosion filter. Such soils have $D_{15 \mathrm{~b}} \geq 0.35 \mathrm{~mm}$, for which $D_{15} \leq \min \left(5 d_{85}\right.$ and $\left.0.5 \mathrm{~mm}\right)$ seems a safe and logical criterion.

- Wherever $d_{85} \geq 0.3 \mathrm{~mm}$ or $S_{\mathrm{c}} \geq 30 \%$ or $F_{\mathrm{c}}<65 \%$, the $D_{15 \mathrm{~b}}$ value from NEF testing is almost always higher than $0.7 \mathrm{~mm}$; thus, the $D_{15} \leq 0.7 \mathrm{~mm}$ criterion is expected to be reliable. This also applies safely to soils with $F_{\mathrm{c}}$ between $65 \%$ and $80 \%$.

- Dispersibility would require $D_{15} \leq 0.3 \mathrm{~mm}$ for soils with $F_{\mathrm{c}} \geq 80 \%$ and $D_{15} \leq 0.5 \mathrm{~mm}$ otherwise.

- The PI has little influence on filtration.

The foregoing conclusions are reflected in the amended criteria summarised in Table 1. The flowchart provided in Figure 17 should also provide useful advice to designers of filters to resist internal erosion in new dams. 


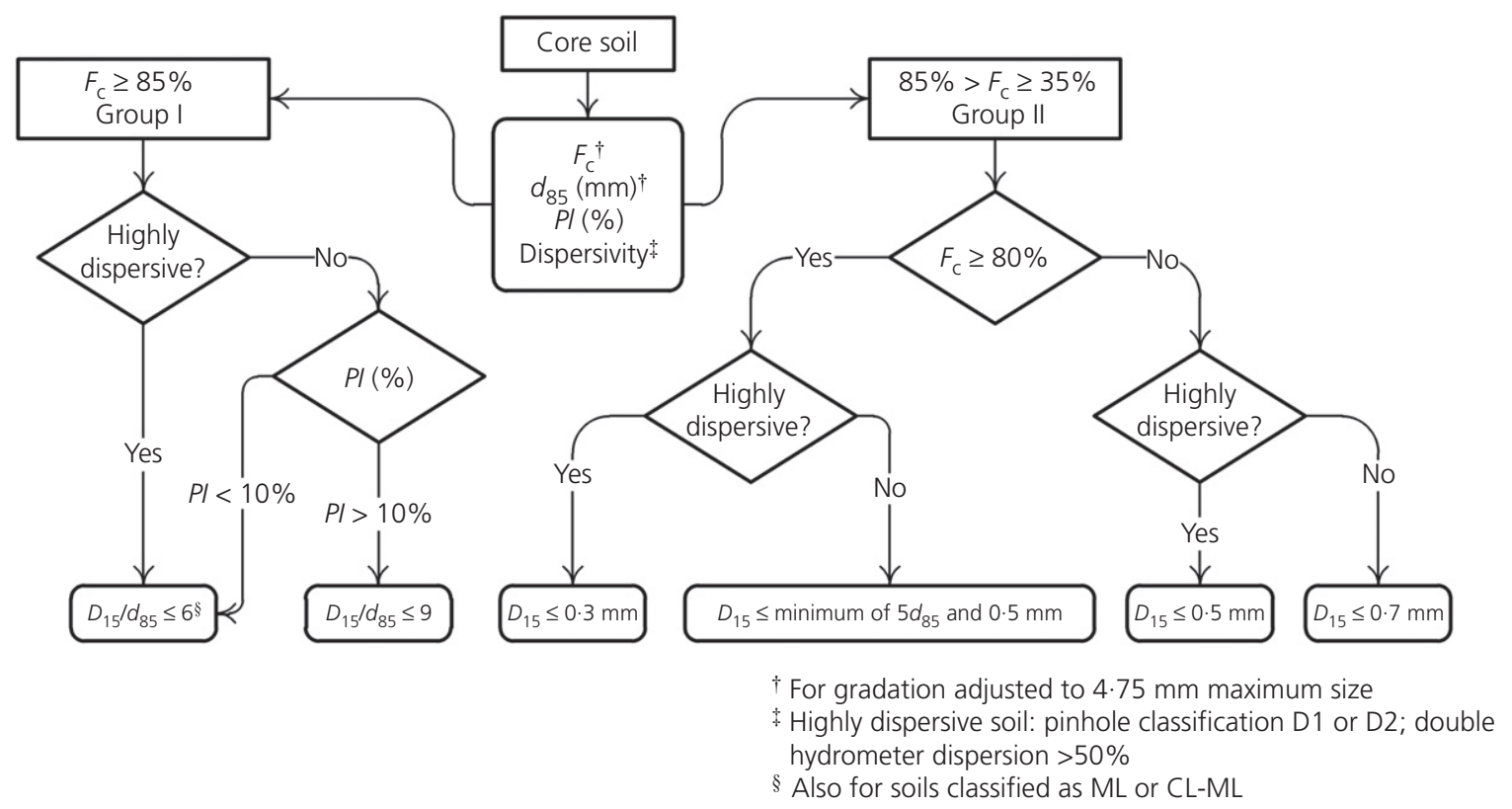

Figure 17. Flowchart for critical filter design of group I and group II core soils

It is important to note that, of the 258 core soils (groups I and II) studied herein, $75 \%$ have $F_{\mathrm{c}} \geq 80 \%$. Furthermore, from 213 core soils with available USCS information, $66 \%$ are CL soils. As already discussed, this unavoidable bias is a result of designers/specialists dealing with NEF tests reported in the literature selecting finer representatives for core soil ranges, which necessitate finer filters.

For embankment dam design, proficient filtration testing supersedes established formulae, on the condition that designed filters are not coarser than the criteria in Table 1. 'If the designer has any doubts concerning the filter's performance, filter tests should be conducted. For example, dispersive soils, very fine grained cohesionless soils, highly plastic soils, and soils prone to desiccation may require extra precautions' (USBR, 2011: p. 53). $\mathrm{NEF}$ tests have been repeatedly performed worldwide and much experience concerning precise, practical NEF testing is available that may pave the way for designers/specialists. Even with overall agreement to the filter criteria provided in Table 1 , the authors strongly advocate filter testing, and particularly NEF tests, for filter substantiation in embankment dams.

Future studies could focus on comparing filter criteria and NEF test results with soil erosion characteristics such as those deduced from hole erosion tests (Wan and Fell, 2004). In addition, it would be effective to associate boundary filters (i.e. $D_{15 \mathrm{~b}}$ ) satisfying NEF tests with filter permeability. Systematic NEF and continuing-erosion filter tests (involving measurements of eroded soil mass) may help bracket a 'some erosion' boundary in terms of filter $D_{15}$ and base soils properties $\left(d_{85}, F_{\mathrm{c}}\right.$ etc. $)$.

\section{REFERENCES}

ASTM (2006a) D 4647M-13: Standard test method for identification and classification of dispersive clay soils by the pinhole test. ASTM International, West Conshohocken, PA, USA.

ASTM (2006b) D 6572-06: Standard test methods for determining dispersive characteristics of clayey soils by the crumb test. ASTM International, West Conshohocken, PA, USA.

ASTM (2011) D 4221-11: Standard test method for dispersive characteristics of clay soil by double hydrometer. ASTM International, West Conshohocken, PA, USA.

Bell FG and Maud RR (1994) Dispersive soils: a review from a South African perspective. Quarterly Journal of Engineering Geology and Hydrogeology 27(3): 195-210.

Delgado Ramos F (2000) Laboratory Simulation of the Internal Erosion Phenomenon to Determine the Variables that Influence the Efficiency of Filters for Cohesive Soils. PhD dissertation, University of Granada, Grenada, Spain (in Spanish).

Delgado Ramos F and Locke M (2000) Design of granular filters: guidelines and recommendations for laboratory testing. In Proceedings of the 3rd International Conference on Filters and Drainage in Geotechnical and Environmental Engineering, Geofilters 2000, Warsaw, Poland (Wolski W and Mlynarek J (eds)). Balkema, Rotterdam, the Netherlands, pp. 115-122.

Delgado Ramos F, Huber NP, Escuder I and De Membrillera MG (2006) Revised criteria for evaluating granular filters in earth and rockfill dams. Proceedings of the 22nd ICOLD Congress, Barcelona, Spain, Q.86-R.29. International Commission on Large Dams, Paris, France, pp. 445-456.

Delgado Ramos F, Poyatos JM and Osorio F (2012) Internal erosion of clayey soils protected by granular filters. Proceedings of the 6th International Conference on Scour and Erosion (ICSE6), Paris, France (Fry JJ and Chevalier C (eds)). Société Hydrotechnique De France, Paris, France, pp. 871-878.

Delgado Ramos F, Escudero-Merino D and Olalla C (2016) The importance of permeability in granular filter design and control. In Proceedings of the 8th International Conference on Scour and Erosion (ICSE8), Oxford, UK (Harris J, Whitehouse R and 
Geotechnical Engineering

Volume 171 Issue GE3
A parametric database study of

no-erosion filter tests

Tabatabaie Shourijeh, Soroush, Shams Molavi

and Ramezani Fouladi
Moxon S (eds)). CRC Press/Balkema, Leiden, the Netherlands, pp. 979-985.

Eskandary H (2011) Experimental Investigation of Filter Design Criteria to Prevent Erosion of Dispersive Soils and Some Factors Influencing the Filtration Performance of Earth Dams. MSc thesis, Zanjan University, Zanjan, Iran (in Persian).

Fan $\mathrm{H}$ and Kong L (2013) Empirical equation for evaluating the dispersivity of cohesive soil. Canadian Geotechnical Journal 50(9): 989-994.

Farzaneh O (2005) Investigation of the No Erosion Filter for the Core Material of Dousti Dam. Tehran University, Tehran, Iran, Technical Report (in Persian).

Farzaneh O (2007) Investigation of the No Erosion Filter for Kaboudval Storage Dam. Tehran University, Tehran, Iran, Technical Report (in Persian).

Farzaneh O (2015) Investigation of the No Erosion Filter for Golmandareh Dam. Tehran University, Tehran, Iran, Technica Report (in Persian).

Fell R, Wan CF, Cyganiewicz J and Foster M (2003) Time for development of internal erosion and piping in embankment dams. Journal of Geotechnical and Geoenvironmental Engineering 129(4): 307-314

Fell R, Foster MA, Cyganiewicz J et al. (2008) Risk Analysis for Dam Safety: A Unified Method for Estimating Probabilities of Failure of Embankment Dams by Internal Erosion and Piping. School of Civil and Environmental Engineering, University of New South Wales, Sydney, Australia, UNICIV Report No. R-446, Version: Delta, Issue 2.

Fell R, Hanson G, Herrier G, Marot D and Wahl T (2013) Relationship between the erosion properties of soils and other parameters. In Erosion in Geomechanics Applied to Dams and Levees (Bonelli S and Nicot F (eds)). ISTE Ltd, London, UK and Wiley, Hoboken, HJ, USA, pp. 343-381.

Fell R, MacGregor P, Stapledon D, Bell G and Foster M (2015) Geotechnical Engineering of Dams, 2nd edn. Taylor \& Francis, London, UK

FEMA (Federal Emergency Management Agency) (2011) Filters for Embankment Dams: Best Practices for Design and Construction. FEMA, Washington, DC, USA

Foster MA and Fell R (1999) Assessing Embankment Dam Filters which do not Satisfy Design Criteria. School of Civil and Environmental Engineering, University of New South Wales, Sydney, Australia, UNICIV Report No. R-376.

Foster M and Fell R (2001) Assessing embankment dam filters that do not satisfy design criteria. Journal of Geotechnical and Geoenvironmental Engineering 127(5): 398-407.

Foster M, Spannagle M and Fell R (1998) Analysis of Embankment Dam Incidents. School of Civil and Environmental Engineering, University of New South Wales, Sydney, Australia, UNICIV Report No. R-374.

Fry JJ (2016) Lessons on internal erosion in embankment dams from failures and physical models. Proceedings of the 8th International Conference on Scour and Erosion (ICSE-8), Oxford, UK (Harris J, Whitehouse R and Moxon S (eds)). CRC Press/Balkema, Leiden, the Netherlands, pp. 41-58.

Fry JJ, Vogel A, Royet P and Courivaud JR (2012) Dam failures by erosion: lessons from ERINOH data bases. Proceedings of the 6th International Conference on Scour and Erosion (ICSE-6), Paris, France (Fry JJ and Chevalier C (eds)). Société Hydrotechnique De France, Paris, France, pp. 273-280.

Hanson GJ, Wahl TL, Temple DM, Hunt S and Tejral R (2010) Erodibility characteristics of embankment materials. Dam Safety 2010, Proceedings of the Association of State Dam Safety Officials (ASDSO) Annual Conference, Seattle, WA, USA. Association of State Dam Safety Officials, Lexington, KY, USA, pp. $43-50$.
Hossieni SA (2000) Determination of Filter Design Criteria for Earth and Rockfill Dams with Central Cores Comprised of Mixed Materials. MSc thesis, Sharif University of Technology, Tehran, Iran (in Persian).

ICOLD (International Commission on Large Dams) (2017) Internal erosion of existing dams, levees and dikes, and their foundations. Bulletin 164, Paris, France. International Commission on Large Dams, Paris, France.

Kamali J (1999) Experimental Investigation of Filter Design Criteria for Dispersive Soils in Embankment Dams. MSc thesis, Tehran University, Tehran, Iran (in Persian).

Khavas MH (1998) Determination of Filter Design Criteria for Earth and Rockfill Dams with Central Cores Comprised of Broadly Graded and Gap Graded Soils. MSc thesis, Sharif University of Technology, Tehran, Iran (in Persian).

Khor CH and Woo HK (1989) Investigation of crushed rock filters for dam embankment. Journal of the Geotechnical Engineering Division, ASCE 115(3): 399-412.

Locke MA (2001) Analytical and Laboratory Modeling of Granular Filters in Embankment Dams. PhD dissertation, University of WollongongWollongong, NSW, Australia.

Mirata T and Gürler T (2004) A modified way of testing filters for clay cores of embankment dams. Electronic Journal of Geotechnical Engineering 9(C): 1-9.

Mitchell JK and Soga K (2005) Fundamentals of Soil Behavior, 3rd edn. Wiley, Hoboken, NJ, USA.

Nasr M (1999) Determination of Filter Design Criteria for Earth and Rockfill Dams with Central Cores Comprised of Broadly Graded and Gap Graded Soils. MSc thesis, Sharif University of Technology, Tehran, Iran (in Persian).

NRCS (Natural Resources Conservation Services) (1994) Gradation design of sand and gravel filters. In National Engineering Handbook, Chapter 26, Part 633. United States Department of Agriculture, Washington, DC, USA.

Ramezani Fouladi S (2016) An Experimental Study of the Relation between Erodibility of Fine Grained Soils and Filter Design Criteria. MSc thesis, Amirkabir University of Technology (Tehran Polytechnic), Tehran, Iran (in Persian).

Regazzoni P, Hanson G, Wahl Tet al. (2008) The influence of some engineering parameters on the erosion of soils. In Proceedings of the 4th International Conference on Scour and Erosion (ICSE-4), Tokyo, Japan (Sekiguchi H (ed.)). Japanese Geotechnical Society, Tokyo, Japan, pp. 442-446.

Richards KS and Reddy KR (2007) Critical appraisal of piping phenomena in earth dams. Bulletin of Engineering Geology and the Environment 66(4): 381-402.

Rowhani M (1996) Empirical Investigation of No Erosion Filters for Dispersive Clay Cores in Embankment Dams. MSc thesis, Tehran University, Tehran, Iran (in Persian).

Shams Molavi S (2013) Filter Criteria Evaluation for Dams with Wet Core for Regions with Humid Climate. MSc thesis, Amirkabir University of Technology (Tehran Polytechnic), Tehran, Iran (in Persian).

Shams Molavi S, Soroush A and Tabatabaie Shourijeh P (2013) Filter design for earth dams: a review of two case histories. Proceedings of the 7th National Congress on Civil Engineering, Zahedan, Iran. University of Sistan and Baluchestan, Zahedan, Iran.

Sherard JL and Dunnigan LP (1985) Filters and leakage control in embankment dams. In Proceedings of a Symposium on Seepage and Leakage from Dams and Impoundments (Volpe RL and Kelly WE (eds)). ASCE, Reston, VA, USA, pp. 1-30.

Sherard JL and Dunnigan LP (1989) Critical filters for impervious soils. Journal of the Geotechnical Engineering Division, ASCE 115(7): 927-947. 
Sherard JL, Dunnigan LP and Decker RS (1976) Identification and nature of dispersive soils. Journal of the Geotechnical Engineering Division, ASCE 102(4): 760-788.

Sherard JL, Dunnigan LP and Talbot JR (1984) Filters for silts and clays. Journal of the Geotechnical Engineering Division, ASCE 110(6): 701-718.

Shourijeh PT and Soroush A (2009) Statistical study of no-erosion filter (NEF) test results. Proceedings of the Institution of Civil Engineers - Geotechnical Engineering 162(3): 165-174, http://dx.doi.org/ 10.1680/geng.2009.162.3.165.

Soroush A and Shourijeh PT (2004) NEF testing on a case study by a relatively large-scale filtration apparatus. Proceedings of the 4th International Conference on Filters and Drainage in Geotechnical and Environmental Engineering, Geofilters 2004, Stellenbosch, South Africa (Fourie AB (ed.)). University of the Witwatersrand, Johannesburg, South Africa, pp. 253-264.

Soroush A and Shourijeh PT (2005) Theoretical and Experimental Evaluation of the Core and Filter Materials of Shamil and Niyan Dams. Amirkabir University of Technology, Tehran, Iran, Technical Report (in Persian).

Soroush A and Shourijeh PT (2009) A review of the no erosion filter test. Geotechnical Testing Journal 32(3): 209-218.

Soroush A, Shourijeh PT and Miri-Disfani M (2006) Filter testing: an essential aspect in designing filters for embankment dams. Proceedings of the 7th International Conference on Civil Engineering, Tehran, Iran. Tarbiat Modares University, Tehran, Iran.

Soroush A, Aminzadeh AH and Shourijeh PT (2008) Identifying low-fines soils not suited to NEF testing. Proceedings of the Institution of Civil Engineers - Geotechnical Engineering161(4): 181-188, http://dx.doi.org/10.1680/geng.2008.161.4.181.

Soroush A, Shourijeh PT and Mohammadinia A (2010a) Theoretical and Experimental Evaluation of the Core and Filter Materials of Siahoo Dam. Amirkabir University of Technology, Tehran, Iran, Technical Report (in Persian).

Soroush A, Shourijeh PT and Mohammadinia A (2010b) Theoretical and Experimental Evaluation of the Core and Filter Materials of Safa Dam. Amirkabir University of Technology, Tehran, Iran, Technical Report (in Persian).

Soroush A, Shourijeh PT, Mohammadinia A and Shams Molavi S (2011a) Theoretical and Experimental Evaluation of the Core and Filter Materials of Mojen Storage Dam. Amirkabir University of Technology, Tehran, Iran, Technical Report (in Persian).

Soroush A, Shourijeh PT, Shams Molavi S and Mohammadinia A (2011b) Theoretical and Experimental Evaluation of the Core and Filter Materials of Harat Storage Dam. Amirkabir University of Technology, Tehran, Iran, Technical Report (in Persian)

Soroush A, Shourijeh PT, Mohammadinia A and Shams Molavi S (2011c) Theoretical and Experimental Evaluation of the Core and Filter Materials of Sombar Storage Dam. Amirkabir University of Technology, Tehran, Iran, Technical Report (in Persian).

Soroush A, Shourijeh PT, Shams Molavi S and Mohammadinia A (2011d) Theoretical and Experimental Evaluation of the Core and Filter Materials of Abivard Storage Dam. Amirkabir University of Technology, Tehran, Iran, Technical Report (in Persian).

Soroush A, Shourijeh PT and Mohammadinia AR (2011e) Controlling internal erosion in earth dams and their foundations: case Studies. Indian Geotechnical Conference, IGC-2011, Kochi, India (Sahoo DK, Santhosh Kumar TG, Abraham BM and Jose BT (eds)). Indian Geotechnical Society, Kochi, Kerala, India, vol. 1, pp. 64-71.

Soroush A, Shourijeh PT, Mohammadinia A and Shams Molavi S (2012a) Theoretical and Experimental Evaluation of the Core and Filter Materials of Chandir Storage Dam. Amirkabir University of Technology, Tehran, Iran, Technical Report (in Persian).
Soroush A, Shourijeh PT and Shams Molavi S (2012b) Theoretical and Experimental Evaluation of the Core and Filter Materials of Rudbar Lurestan Dam. Amirkabir University of Technology, Tehran, Iran, Technical Report (in Persian).

Soroush A, Shourijeh PT, Aghajani HF, Mohammadinia AR and Aminzadeh AH (2012c) A review of the sand castle test for assessing collapsibility of filters in dams. Geotechnical Testing Journal, ASTM International 35(4): 503-516.

Soroush A, Shams Molavi S and Tabatabaie Shourijeh P (2014) Filter design for wet core embankment dams in wet climates. Proceedings of International Symposium on Dams in Global Environmental Challenges, Bali, Indonesia. Indonesian National Committee on Large Dams, Jakarta, Indonesia, pp. II-137-II-146.

Soroush A, Shourijeh PT, Shams Molavi S and Ramezani Fouladi S (2015) Theoretical and Experimental Evaluation of the Core and Filter Materials of Beshghardash Earthfill Dam. Amirkabir University of Technology, Tehran, Iran, Technical Report (in Persian).

Soroush A, Shourijeh PT and Shams Molavi S (2016) Applicability of filter design criteria for wet core embankment dams in wet climates. Geotechnical Testing Journal 39(3): 343-361.

USACE (United States Army Corps of Engineers) (2004) EM 1110-2-2300. General Design and Construction Considerations for Earth and Rock-Fill Dams. USACE, Washington, DC, USA.

USBR (United States Bureau of Reclamation) (2004) Evaluation of Protective Filter Erosion Boundaries. Dam Safety OfficeUSBR, Washington, DC, USA, Report No. DSO-04-03.

USBR (2011) Protective filters. In Design Standards No. 13 Embankment Dams. USBR, Washington, DC, USA, Chapter 5 (Phase 4).

USBR (2015) Best Practices in Dam and Levee Safety Risk Analysis. US Department of the Interior, Bureau of Reclamation and US Army Corps of Engineers, USBR, Washington, DC, USA, Version 4.

Vakili AH and Selamat MRB (2014) An assessment of veracity of filter criteria for earth dams. Proceedings of the Institution of Civil Engineers - Geotechnical Engineering 167(6): 574-584, http://dx. doi.org/10.1680/geng.13.00119.

Vakili AH, Bin Selamat MR and Abdul Aziz HB (2015) Filtration of broadly graded cohesive dispersive base soils. Journal of Geotechnical and Geoenvironmental Engineering 141(5), https://doi. org/10.1061/(ASCE)GT.1943-5606.0001280.

Wan CF and Fell R (2004) Investigation of rate of erosion of soils in embankment dams. Journal of Geotechnical and Geoenvironmental Engineering 30(4): 373-380.

\section{How can you contribute?}

To discuss this paper, please email up to 500 words to the editor at journals@ice.org.uk. Your contribution will be forwarded to the author(s) for a reply and, if considered appropriate by the editorial board, it will be published as discussion in a future issue of the journal.

Proceedings journals rely entirely on contributions from the civil engineering profession (and allied disciplines). Information about how to submit your paper online is available at www.icevirtuallibrary.com/page/authors, where you will also find detailed author guidelines 